\title{
Climatology of easterly wave disturbances over the tropical South Atlantic
}

Article

Accepted Version

Gomes, H. B., Ambrizzi, T., Pontes da Silva, B. F., Hodges, K., Silva Dias, P. L., Herdies, D. L., Silva, M. C. L. and Gomes, H. B. (2019) Climatology of easterly wave disturbances over the tropical South Atlantic. Climate Dynamics, 53 (3-4). pp. 13931411. ISSN 0930-7575 doi: https://doi.org/10.1007/s00382019-04667-7 Available at https://centaur.reading.ac.uk/76413/

It is advisable to refer to the publisher's version if you intend to cite from the work. See Guidance on citing.

To link to this article DOI: http://dx.doi.org/10.1007/s00382-019-04667-7

Publisher: Springer

All outputs in CentAUR are protected by Intellectual Property Rights law, including copyright law. Copyright and IPR is retained by the creators or other copyright holders. Terms and conditions for use of this material are defined in the End User Agreement.

\section{www.reading.ac.uk/centaur}

\section{CentAUR}

Central Archive at the University of Reading 
Reading's research outputs online 


\title{
Climatology of Easterly Wave Disturbances over the Tropical South Atlantic
}

\begin{abstract}
Helber B. Gomes ${ }^{1}$, Tércio Ambrizzi², Bruce F. Pontes da Silva ${ }^{3}$, Kevin Hodges ${ }^{4}$, Pedro L. Silva Dias ${ }^{2}$, Dirceu L.
\end{abstract} Herdies $^{5}$, Maria Cristina L. Silva ${ }^{1}$ and Heliofábio B. Gomes ${ }^{1}$

1. Institute of Atmospheric Sciences, Federal University of Alagoas, Maceió, Brazil

2. Department of Atmospheric Sciences, University of Sao Paulo, São Paulo, Brazil

3. Capixaba Institute of Research, Technical Assistance and Rural Extension, Vitoria, Brazil

4. Department of Meteorology, University of Reading, Reading, England

5. National Institute for Space Research, Cachoeira Paulista, Brazil

\begin{abstract}
A 21-yr climatology of Easterly Waves Disturbances (EWDs) over the Tropical South Atlantic (TSA) has been examined using data from the European Centers for Medium-Range Weather Forecasting (ECMWF) interim reanalysis (ERAI) and satellite data. This includes the frequency distribution of EWDs and their interannual variability. The largescale environment associated with EWDs has been investigated for the coastal region of Northeast Brazil (NEB) for the rainy (April-August) season using a composite analysis. EWDs were first identified in ERAI, resulting in 518 observed cases. These were found to show notable interannual variability with around 16-40 episodes each year and with an average lifetime of 4-6 days. Of the identified EWDs, $97 \%$ reached the coast of NEB, of which $64 \%$ were convective in nature and 14\% moved across the NEB region and reached the Amazon. The annual occurrence of EWDs seems to be lower (higher) during El Niño (La Niña). The monthly occurrence of EWDs shows higher activity in the rainy season. EWDs originate in association with five types of system: cold fronts, convective clusters from the west coast of Africa, Intertropical Convergence Zone and Tropical Upper Tropospheric Cyclonic Vortices. The composite analysis indicates strong relative vorticity (RV) and divergence anomalies at low levels, as well as in the vertical profiles of relative humidity and vertical velocity (omega). The precipitation composites show that the EWDs propagate between the TSA and NEB and contribute at least $60 \%$ of the total rainfall over the east coast of NEB throughout the rainy season.
\end{abstract}

Keywords: Easterly waves disturbances, tropical south Atlantic, northeast Brazil and climatology 


\section{Introduction}

The Northeast Brazil (NEB, Fig. 1a) experiences a large contrast in climate, with wet tropical conditions along the coastline and a semiarid climate over the inland areas. The coastal region experiences either severe drought or heavy rainfall during certain periods, causing problems to agriculture, tourism and the local economy in general. The eastern coast of NEB (ENEB) is characterized by high annual rainfall values ( $2000 \mathrm{~mm}$ ), while other parts of NEB, including the region known as "the drought polygon", which occupies approximately $80 \%$ of the total area, does not exceed 500$600 \mathrm{~mm}$ (Fig. 1b ). This variability is associated with different atmospheric teleconnections that affect the region at different times throughout the year, associated with the El Niño-Southern Oscillation (ENSO) (Trenberth 1997; Pezzi and Cavalcante 2001) and sea surface temperature (SST) anomalies over the tropical Atlantic (Servain 1991; Nobre and Shukla 1996).

The rainy season of the North and Semi-arid NEB (Fig. 1c) occurs approximately from February to May. However, the northern area exhibits higher rainfall values relative to the semiarid region due the direct influence of the Intertropical Convergence Zone (ITCZ) (Santos e Silva et al. 2014). On the other hand, the ENEB is strongly influenced by atmospheric disturbances in the easterly flow, typical of tropical latitudes influenced by the trade winds. The ENEB includes the states of Alagoas (AL) and Sergipe (SE) and the eastern Bahia (BA), Pernambuco (PE), Paraiba (PB) and Rio Grande do Norte (RN) (indicated in Figure 1). The rainy season over this region occurs between April and July (Fig. 1b) associated with cold/stationary fronts or their remnants (Kousky 1979), land and sea breeze's (Kousky 1980), and according to Pontes da Silva (2011) and Gomes et al. (2015), primarily associated with Easterly Wave Disturbances (EWDs). Some wave disturbances in the equatorial region have been associated with Mixed Rossby Gravity Waves (MRGW) in the Atlantic Ocean (Silva et al. 2002; Raupp and Silva Dias 2005). These waves are strongly coupled to convection and clearly show an intense cross equatorial flow with stronger asymmetric divergence anomalies straddling the equator. A similar association was found for EW and MRGW in the Northern Hemisphere. For example, Yang et al. (2018) found a connection between African easterly waves (AEW), equatorial westward-moving MRGW and equivalent barotropic Rossby waves from the Southern Hemisphere.

EWDs are synoptic-scale quasi-periodic perturbations occurring within the trade wind regime and are most prominent during the ENEB rainy season. They are characterized by an average period of 5.5 days and wavelengths around $4500 \mathrm{~km}$ (Gomes et al. 2015). EWDs are climatologically important because they carry large amounts of moisture to areas that are generally dry, such as the Caribbean. When the EWDs interact with local circulations induced by topography, low-level convergence can occur, resulting in increased rainfall over the eastern and northern NEB coasts.

According to Berry et al. (1945) and Asnani (1993), these disturbances occur throughout the tropical lower troposphere, although they vary in size and intensity, depending on the season and region. In the Tropical South Atlantic (TSA), Yamazaki and Rao (1977) determined that the EWDs peak frequency occurs in the fall and austral winter, while Diedhiou et al. (2010) showed that they are weaker relative to Atlantic Northern Hemisphere EWDs, which occur mostly from May to August. In most cases, EWDs can be identified in satellite imagery as cloud clusters with shallow vertical growth, advancing from the eastern TSA and occasionally intensifying when they reach the ENEB, generating clouds with strong vertical development (Molion and Bernardo, 2002). In some cases, EWDs move toward the continent with pre-existing convective cloudiness over the sea, but losing strength as they enter the continent. According to Merritt (1964), it is possible to see that the EWDs do not appear to have uniform characteristics, even in relation to their association with convection. This has resulted in some authors proposing that the eastern disturbances in the TSA may not be EWDs, but some other kind of tropical disturbance (Merritt 1964; Molion and Bernardo 2002).

Several studies have shown that EWDs occur in various tropical regions, in the western Pacific Ocean, Caribbean Sea, West Africa, and eastern Atlantic Ocean (Riehl 1954; Carlson 1969; Burpee 1972; Reed et al. 1977; Krishnamurti 1979; Thorncroft 1995; Thorncroft and Hodges 2001, Berry et al. 2007; Serra et al. 2008, 2010). In the TSA, some studies have provided a better understanding of the formation and maintenance of EWDs (Yamazaki and Rao 1977; Hall 1989; Chan 1990; Santos et al. 2002; Kayano 2003; Raupp and Silva Dias 2005; Coutinho and Fisch 2007; Diedhiou et al. 2010; Torres and Ferreira 2011; Pontes da Silva 2011; Caetano 2011; Gomes et al. 2015). According to Asnani (1993), the major difficulties in the study of EWDs are: a) their relatively weak intensity: EWDs have lower amplitudes compared to the semi-stationary troughs and ridges of tropical latitudes and it is hard to identify them on synoptic charts in some cases; b) the absence of a homogeneous structure: EWDs are embedded in the zonal flow which has a different structure in different seasons and longitudes. If the eastern flow is shallow (deep), only weak (intense) EWDs are expected; c) sparse data in the tropics: most of the tropical region is covered by oceans, where it is difficult to establish meteorological observations with radiosondes. Even over land, the meteorological station density is limited, which makes it essential to make use of satellite data over the desert and ocean areas.

An important motivation for this study of the variability of EWDs is related to the marked seasonal and interannual variability of precipitation over the NEB coast (e.g., Rao et al. 1993; Lucena et al. 2011). Since EWDs are a dominant synoptic-scale system in the region, especially in the rainy season (April-July), it is important to investigate the EWDs contribution to precipitation during this period. Pontes da Silva (2011) studied the EWDs contribution to the precipitation in ENEB in the rainy season from 2006 to 2010, and showed an average occurrence of 23 EWDs cases during the rainy season with small interannual variability, with each EWD case resulting in an average precipitation of 16 to $20 \mathrm{~mm}$ between the PE state coastline and eastern RN state coast. The Pontes da Silva (2011) study also showed that the EWDs are responsible for $70 \%$ of the rainfall during the rainy season between the AL state coast and the eastern 
RN state, but did not find a significant contribution in latitudes further south of the eastern BA state. Another motivation for considering the interannual variability of EWDs concerns the relationship between EWD activity and ENSO episodes. Coutinho and Fisch (2007) suggest that these disturbances may be associated with ENSO episodes, i.e., higher (lower) EWDs occur in La Nina (El Nino) years. They documented that during La Nina (El Nino) years the EWDs frequency were higher (lower) and associated with positive (negative) annual precipitation anomalies over Alcântara-MA.

In relation to the life cycles of EWD, Gomes et al. (2015) investigated their main characteristics, including genesis, dissipation and tracking during the 2006 and 2007 rainy season over the TSA using an automated tracking technique (Hodges 1995, 1999) applied to ERA-Interim reanalysis data. They showed that the tracks of these systems can be seen all over ENEB, especially between SE and MA states, and between the NEB coast (northern and eastern) and into the continent, while the genesis showed different formation regions from one year to another. The automatic tracking managed to capture $71 \%$ of EWDs in all periods, indicating that this method applied to reanalyzes may be effective for identifying and tracking these waves in the TSA.

The main objective of this paper is to present a 21-yr EWD climatology over the TSA based on the period 1989-2009, which extends the work of Gomes et al. (2015), including a description of the interannual variability of EWD activity. Additionally, we will present the synoptic-scale and dynamic characteristics associated with them for the ENEB rainy season and a comparison between the subjective and objective EWDs identification methods.

The paper is organized as follows. Section 2 outlines the data and methodology. Section 3 shows the EWD climatology for 1989-2009, including their characteristics, interannual variability and composites for rainy season. In section 4 we focus on the EWD climatology based on the tracking statistics. The results are summarized and further discussed in section 5 .

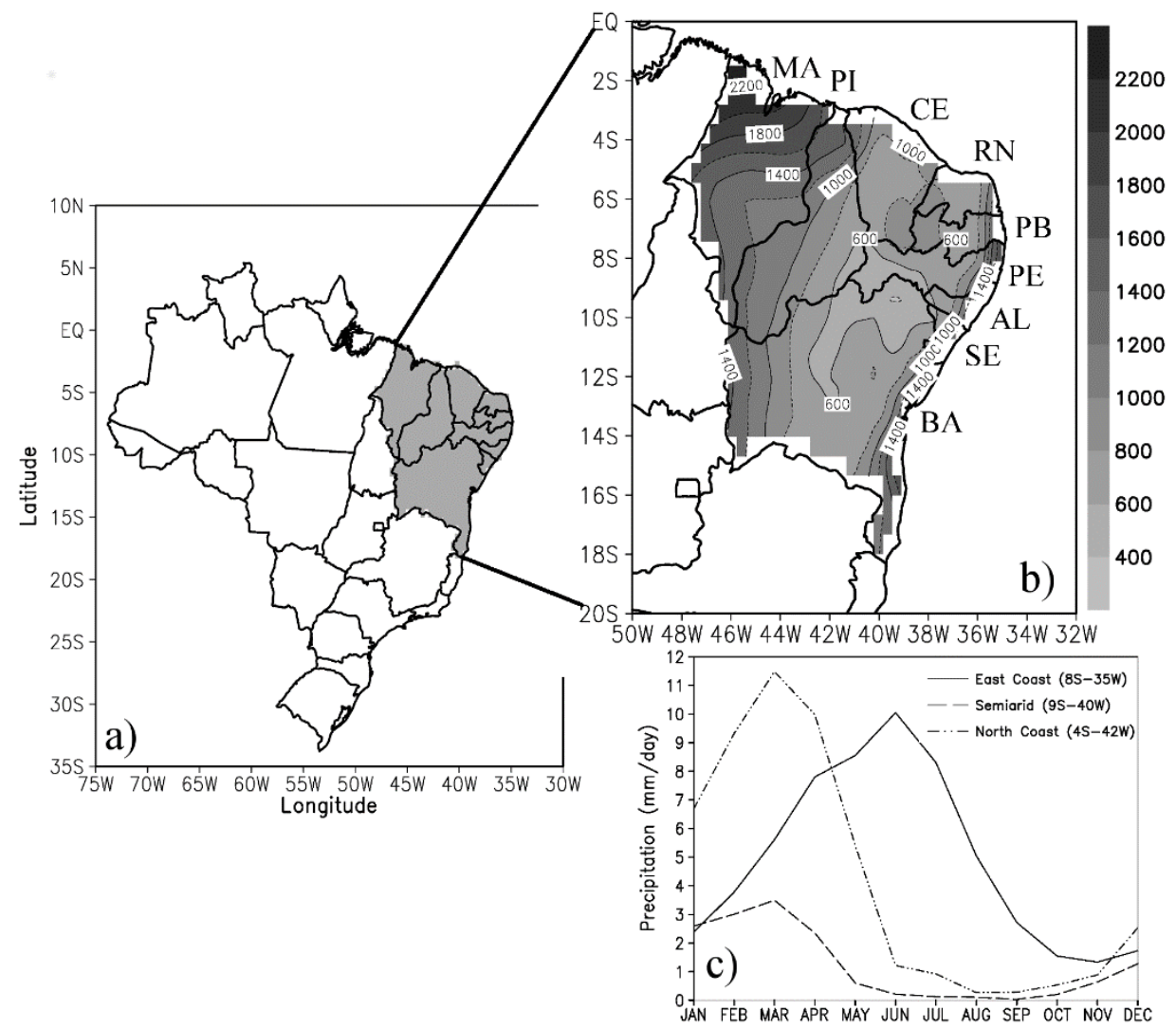

Fig. 1 Northeast Brazil geographical location and study area (a) and annual (b) and monthly (c) precipitation climatology.

\section{Data and methods}

a. Data

To subjectively (manual) identify the EWDs and analyze the cloud and synoptic-scale systems associated with them, Meteosat 3, 4, 5, 6, 7, 8 and 9 satellite images with 3 hour temporal resolution in the visible $(0.5-0.9 \mu \mathrm{m})$, water vapor $(5.7-7.1 \mu \mathrm{m})$, and infrared $(10.5-12.5 \mu \mathrm{m})$ channels are used. These data were obtained through the Global International Satellite Cloud Climatology Project (ISCCP) B1 Browse System/National Climatic Data Center/National Environmental Satellite, Data, and Information Service/National Oceanic and Atmospheric Administration (GIBBS/NCDC/NESDISS/NOAA). 
In order to study the EWDs horizontal and vertical structures data from the European Centers for MediumRange Weather Forecasting (ECMWF) interim reanalysis (ERAI, Simmons et al. 2007a,b; Uppala et al. 2008) is used. The ERAI is produced with a sequential 4-Dimensional Variational (4-D Var) data assimilation scheme, advancing forward in time using a 12-hour analysis cycle (Dee et al. 2011). The data are arranged on a $0.75^{\circ} \mathrm{x} 0.75^{\circ}$ grid with 60 vertical levels and is available from 1979 to the present with a time step of six hours. Here, only the period 1989-2009 is considered. As the current research focuses on EWDs, we chose to use horizontal winds, relative vorticity and divergence fields at 1000, 925, 850, 700, 600, 500 and $200 \mathrm{hPa}$, as well as the vertical profiles of relative humidity (RH) and the vertical motion (omega) between 1000 and $200 \mathrm{hPa}$. The EWD vertical structure is investigated using vertical profiles along the latitude of $7^{\circ} \mathrm{S}$ from 1000-200 hPa. The EWD contribution to rainfall over the TSA and NEB regions is evaluated using precipitation from both the Tropical Rainfall Measuring Mission (TRMM, Huffman et al. 2001), from algorithm 3B42, which is available on a $0.25^{\circ} \times 0.25^{\circ}$ grid for the period 1998-2009 and ERAI with 12 hourly accumulations of total precipitation. Also used is the daily mean outgoing longwave radiation (OLR) data from the National Oceanic and Atmospheric Administration (NOAA) polar-orbiting meteorological satellites, available on a regular grid of $2.5^{\circ} \times 2.5^{\circ}$ (Liebmann and Smith 1996). Although the length of the TRMM database is smaller than the period of this study, they were used to verify how well the ERAI precipitation matches to the satellite based precipitation product.

\section{b. Methods}

Observed EWD cases are obtained following the method of Pontes da Silva (2011) and Gomes et al. (2015). First, the EWD cases were detected based on the Meteosat satellite images with $3 \mathrm{~h}$ time interval by considering the cloudiness and characteristic disturbance scale of EWDs which move westward over the TSA. The analysis area covers almost the whole tropical Atlantic ocean, from Africa to northern Brazil, from $30^{\circ} \mathrm{E}$ to $45^{\circ} \mathrm{W}$ and between $10^{\circ} \mathrm{N}$ and $40^{\circ} \mathrm{S}$, but for display the satellite images and meteorological fields were more restricted to better illustrate the synoptic systems in the analysis.

The EWs cloudiness characterization of Hall (1989) suggested the existence of four unique areas: 1) a ridge area associated with fair weather and high visibility, with surface divergent flow, subsidence and low cumulus $(\mathrm{Cu})$ humilis clouds; 2) the region near the trough axis, where growing $\mathrm{Cu}$ clouds, cirrus ( $\mathrm{Ci}$ ) and altocumulus (Ac) predominate with reasonable visibility, however showing a sparse rainfall; 3) an area near the trough with the presence of $\mathrm{Cu}$ congestus, $\mathrm{Ci}$ and $\mathrm{Ac}$ and frequent rain and 4) the region behind the trough axis, with convergent flux and strong upward movement, presenting cumulonimbus $(\mathrm{Cb})$ and moderate to intense precipitation. Merritt (1964) observed five different distributions of cloudiness associated with tropical disturbances, showing that not all EWs have convective cloud bands at the synoptic scale (because of this we chose not to use long wave radiation in our observational analysis) Often, these systems only contain mesoscale shallow clouds during certain periods, displaying convective clouds at other periods. According to Merrit (1964), some EWs have no significant cloud cover at any stage of their life cycle but it does not mean that they are necessarily weak disturbances in synoptic fields such as vorticity. Still, EWs usually have a characteristic cloudy area standing out from other systems. This cloudiness may be predominantly stratiform or cumuliform, depending on the environment in which the waves are propagating. According to Asnani (1993), cloudiness and precipitation associated with EWs are commonly mixed with the Intertropical Convergence Zone (ITCZ) cloudiness and rainfall.

In this study, the subjective identification of EWDs occurs in the same way as in Pontes da Silva (2011) and Gomes et al. (2015) by considering the reverse temporal direction in most cases, i.e., by animating satellite images backward from the moment in which the wave is best characterized by the cloud cover with synoptic or subsynoptic dimensions, including or not Cbs (rarely it was noticed total absence of Cbs next the NEB coast). The OLR is not used here mainly because at many times just small cloud clusters $(\mathrm{Cu}$ and $\mathrm{Sc})$ were identified, especially during the generation (date/time when the cloudiness was first detected by satellite imagery) and dissipation (date/time of the cloudiness dissipation) stages. Because we are interested in the impact of EWDs over NEB, only the EWDs associated with clouds that have attained this area were considered. An example of EW detection in the IR satellite imagery is presented in Fig. 2. We can see initially low clouds associated with the EW on 1200 UTC 21 and 0300 UTC 22 May 2006 (Figs. 2a-b). In the next hours, there is the development of Cbs in the EW area as the EWD gets closer to ENEB on 0900 UTC 23 and 0300 UTC 24 May (Figs. 2c-d). 

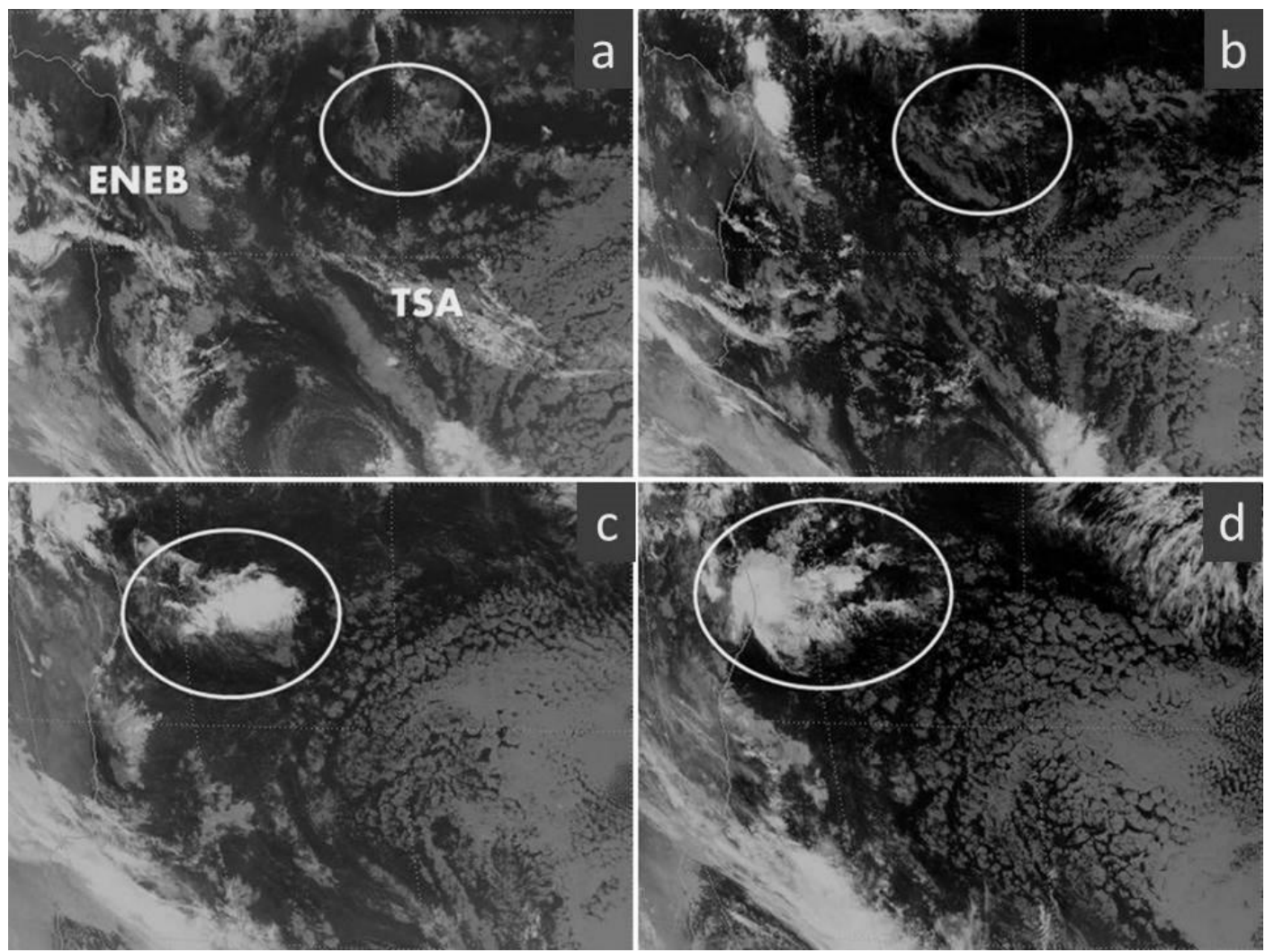

Fig 2. Infrared channel satellite images from METEOSAT-7 at 1200 UTC 21 (a), at 0300 UTC 22 (b), at 0900 UTC 23 (c) and at 0300 UTC 24 (d) of May 2006. The ellipses indicate the cloudiness associated with the EWs propagating over the TSA till its arrival in ENEB.

Potential EWD events were selected from all those identified in the satellite imagery and analyzed in terms of the ERAI relative vorticity and streamline fields at 1000, 925, 850, 700, 600, 500 and $200 \mathrm{hPa}$ to find typical EWD circulation patterns. Those cases with the above characteristics were classified as EWDs. The EWDs are first identified and classified before their climatology (21 years) is examined, including their life cycle, and their distribution by year and month. Those EWDs that reach the ENEB are examined in detail including the type of meteorological systems that they originate from, and which ones reach the Amazon region, as well as whether they are associated with convection or are non-convective.

In order to study the average synoptic-scale and dynamical environments of EWD development, composite anomaly maps of horizontal relative vorticity, horizontal divergence, precipitation, OLR, vertical profiles of RH and omega were generated based on the rainy (April-August) season in ENEB. The selection of the rainy season was based on the monthly EWD frequency (described in section 3.1) and their contribution to precipitation totals over the TSA and ENEB regions (described in section 3.2). The composites were generated from the daily average data of all dates with EWD occurrences, except for precipitation, which used daily accumulations from 4 days prior (-4) to the event day (i.e., when the EWDs reached the ENEB) and each day until 4 days after $(+4)$, although we will only consider here from day -2 until day +2 to reduce the time step (a lot of figures). The anomalies were computed using arithmetic differences between the composites with and without EWDs with the aim of amplifying the signal.

EWDs across the TSA are also determined using the objective feature tracking of Hodges (1995, 1999), which uses relative vorticity to identify the EWDs as minima to contrast with the subjectively identified EWDs. Gomes et al. (2015) were the first to use this automatic tracking algorithm to detect EWDs in the South Atlantic with an emphasis on the ENEB. The identification and tracking criteria used for EWDs presented here is the same as Gomes et al. (2015). As the amplitude of EWDs is usually lower in the Southern Hemisphere compared to EWDs in the Northern Hemisphere, the setup of the tracking algorithm is different to its use in previous studies of African Easterly Waves (AEW) (Thorncroft and Hodges 2001). The main changes is in the resolution at which the tracking algorithm is applied which is changed from T42 $(\sim 310 \mathrm{~km})$ to T63 $(\sim 210 \mathrm{~km})$ and the minimum distance traveled is reduced to at least $500 \mathrm{~km}$ $\left(\sim 5^{\circ}\right)$ and persist for at least 1.5 days. In this study, the algorithm was applied at the $850 \mathrm{hPa}$ level, where the relative vorticity centers are most intense and better identified.

\section{Easterly wave disturbances climatology}

\subsection{Climatological characteristics}

The initial identification, based on the satellite imagery, found 518 EWDs over the 21year period (1989-2009) of analysis, with an interannual variability of around 16-40 EWDs with average lifetimes of 4-6 days and standard 
deviation of around 6. Of the 518 identified EWDs $504(97 \%)$ reached the ENEB at some point in their evolution, and $330(64 \%)$ were found to be associated with convection and $70(14 \%)$ crossed the NEB region and reached the Amazon region.

Figure 3 displays the distribution of the 518 cases by year, month and the type of subjectively identified meteorological system associated with their formation. From Fig. 3a it is clear that there is a large interannual variability in the number of EWDs, especially with ENSO episodes, such as during La Niña (El Niño) in the years 1989, 1996, 1999, 2000, 2001, 2006 and 2008 (1991, 1992, 1993, 2003 and 2005) where they are generally higher (lower) in number. However, in 1995, 1998 and 2007 this relation seems less clear (black bars), which may be due to the presence of both events (La Niña and El Niño) in the same year. The ENSO years are defined from the December/January period which is before the rainy season based in the NINO3.4 index. Caetano (2011), using an observational analysis, examined EWDs for the period 1999-2009 and also identified high variability in the annual occurrence of between 5-51 EWDs and 376 cases in total. The difference between the study of Caetano (2011) and that reported here may be linked to the different identification criteria used for the EWDs by Caetano (2011), such as the life cycle, which considered the EWDs genesis and growth when some system moves eastward for at least 6 and 12 hours, respectively.

Figure $3 b$ illustrates the monthly distribution of EWDs numbers for the 21 analyzed years. As already discussed in previous studies (eg. Pontes da Silva 2011; Gomes et al 2015), a higher occurrence is observed between April and July, however, it is clear that August (64 cases) also has a high frequency of EWDs cases. This confirms that EWDs are an important weather system for the ENEB rainy season (429 cases; April-August) compared to the other months ( 89 cases; dry season). Between the months of October and December the EWDs are very infrequent (less than 4 cases).

Figure $3 c$ illustrates the distribution of system types that are connected with the origin of the EWDs, i.e, before and at the time that the EWDs were identified. We have subjectively identified four types of associated systems, such as Upper Tropospheric Cyclonic Vortices (UTCV, 8 cases-1,54\%), Intertropical Convergence Zone (ITCZ, 33 cases6,37\%), convective clusters from the west coast of Africa (AF, 52 cases-10,04\%) and Cold Fronts (CF, 374 cases$72,20 \%)$. EWD formation was also observed through the interaction of AFs and CFs (15 cases-2,90\%), AF and ITCZ (18 cases-3,47\%), AF/UTCV (2 cases-0,39\%) and ITCZ and CF (16 cases-3,09\%). It seems that the main system associated with EWD formation are CFs and that approximately $91 \%$ of the 72 are formed in the rainy season (AprilAugust), where $61 \%$ were convective. During the dry period, $9 \%$ of the 72 EWDs associated with CFs formed between September-March, while those associated with convection were rare. This result is expected, since the extension to the equator of a midlatitude trough (frontal troughs, moving westwards with the trade winds) or tropical latitude trough extension to the poles (which may be associated with the equatorial trough) are connected with EWD formation in many cases (Yamazaki and Rao 1977; Asnani 1993; Fedorova 2008b). It is exactly during the rainy season (austral autumn and winter) that the most intense CFs tend to move towards lower latitudes, disturbing the trade winds. Other important systems associated with EWD formation are the convective clusters from western Africa ( $90 \%$ of them were convective). Severe thunderstorms that develop mainly over middle Africa appear to have an important role in some EWD formation over the TSA. Some troughs associated with these storms propagate over the TSA disturbing the trade winds, later reaching the ENEB. Although we have discussed the system type associated with EWD development, it is not the focus of this work to analyze the characteristics of their life cycle. A more detailed analysis of the origin of the EWDs will be reported in a future paper.

(a)

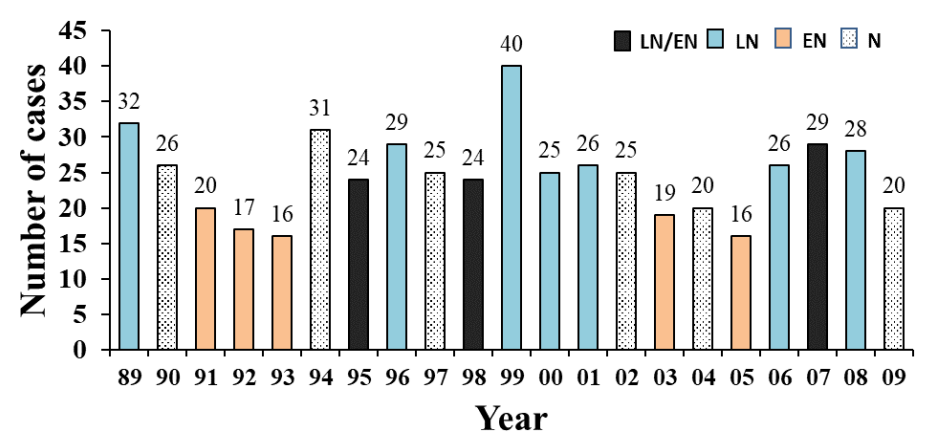

(b) 


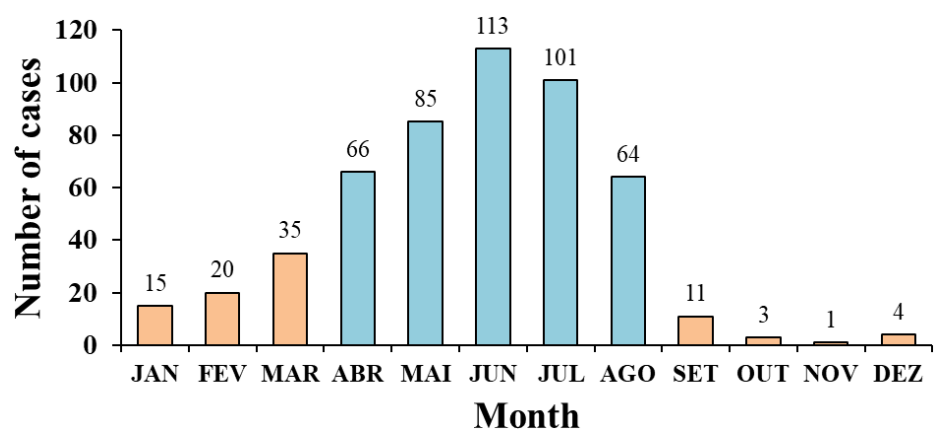

(c)

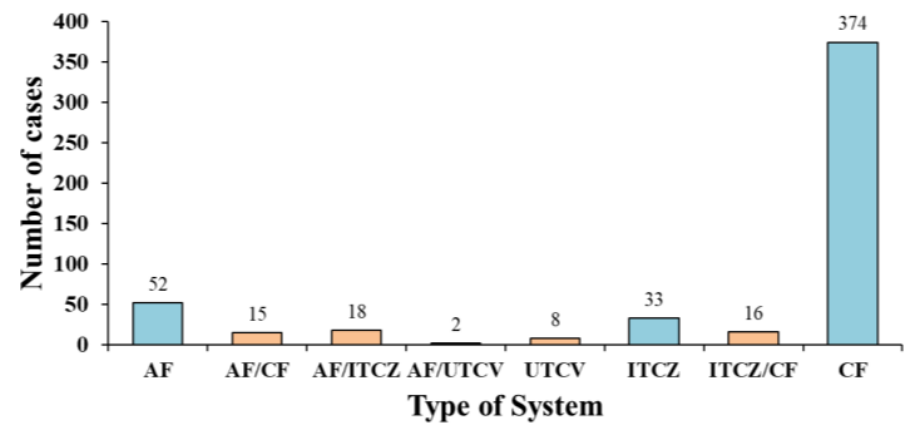

Fig. 3 Distribution of EWDs observed cases for the period 1989-2009 by year (a), month (b) and types of systems they originate from (c). (CF - Cold Fronts; ITCZ - Intertropical Convergence Zone; AF - convective clusters from the west coast of Africa; UTCV - Upper Tropospheric Cyclonic Vortices). The numbers over the bars represent the cases frequency.

\subsection{EWD Composites}

The composites show the gradual and progressive mean evolution on time of a data set, which can be applied in atmospheric variables The composites allow the key components to be identified of both developing and nondeveloping EWDs and their characteristics and structure to be compared. The composites also help to identify the average synoptic scale and dynamic environment through the development stage during the rainy (April-August) ENEB season of 518 EWDs. The ERAI data was used to generate daily EWDs composites for day -2 to day +2 , where the day 0 refers to the date when the EWDs are closest to the ENEB coastline. As will be shown, the EWDs intensify near NEB and quickly decay after reaching the continent, having an average lifetime of five days and staying near ENEB for at least 2-3 days.

The choice of the rainy season is based on the monthly EWD frequency (Fig 3b; observational analysis) and the precipitation anomalies due to EWDs (lag 0 up to lag +4) over the ENEB and the TSA for the period 1989-2009 (Figure 4). These anomalies were computed from TRMM and ERAI data for the same periods using the arithmetic differences between total precipitation associated with and without EWDs for each month. As the results were similar for both data sets, except that the intensity of the anomaly for the TRMM data is weaker, only the results for ERAI will be presented in Figure 4. From these results, it seems that the EWDs contribution (positive anomaly) to precipitation between April and August (Figs 4d-h) is mainly between Alagoas and the Ceará state coasts, in contrast to the other months (negative anomaly). Through the rainy season the EWDs contribute to the precipitation over the Pará and Amapá states in agreement with the results obtained in the observational analysis (see section 3.1) which identified 14\% of the EWDs that crossed the NEB region and reached the Amazon region. Thus, in order to verify the differences between the atmospheric fields, such as relative vorticity, streamlines convergence/divergence horizontal and vertical cross-section of the relative humidity and omega, in the presence and absence of EWDs, we also generate composite anomaly maps during the rainy season (April-August).

(a)

(e) (i) 


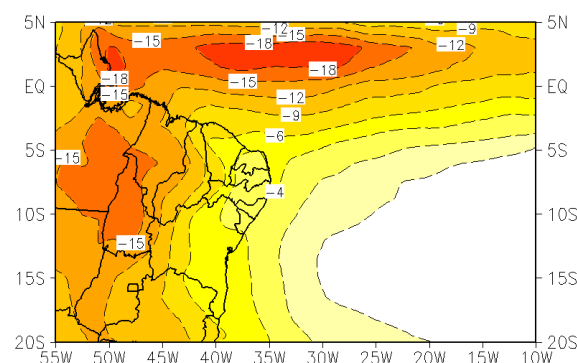

(b)

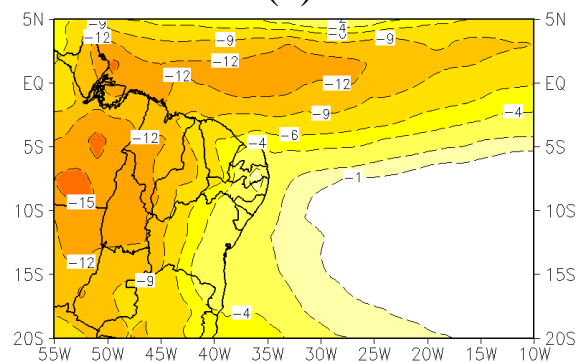

(c)

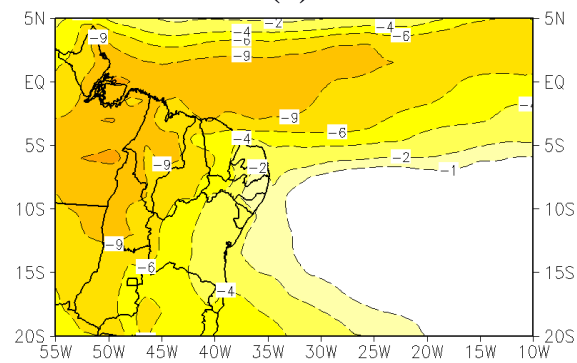

(d)

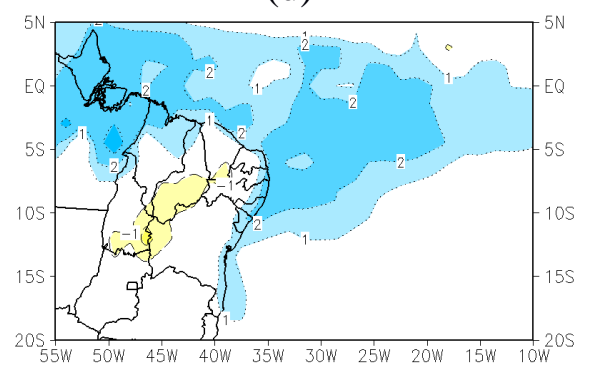

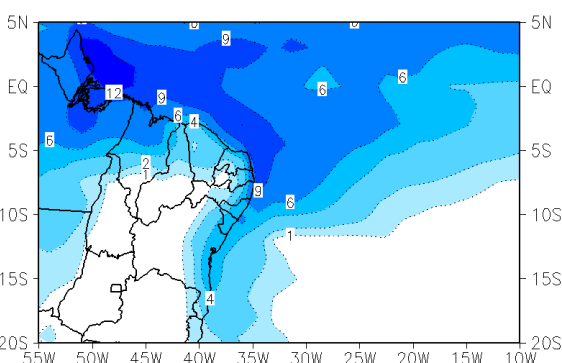

(f)

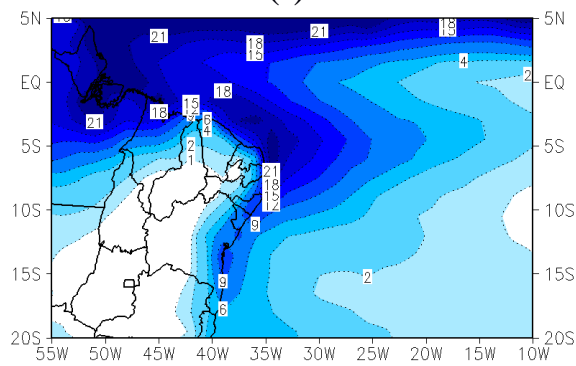

$(\mathrm{g})$

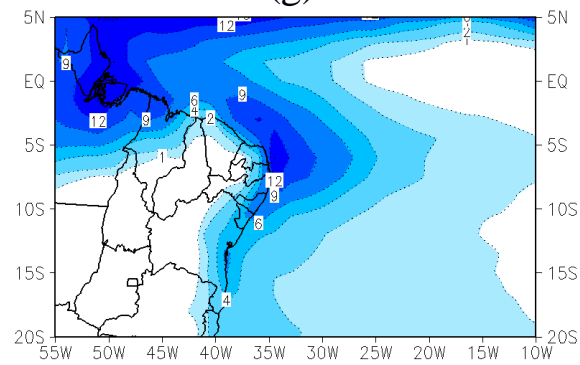

(h)

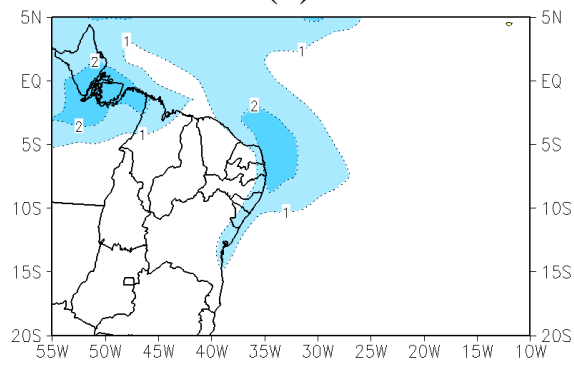

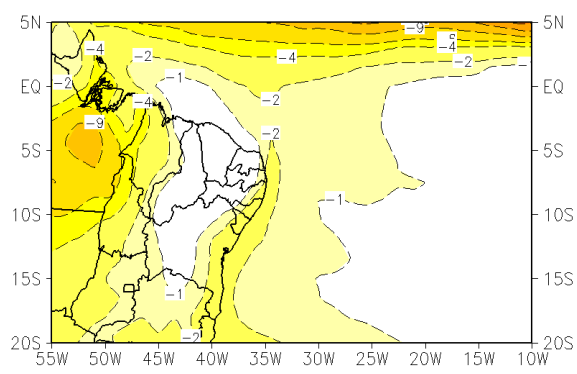

(j)

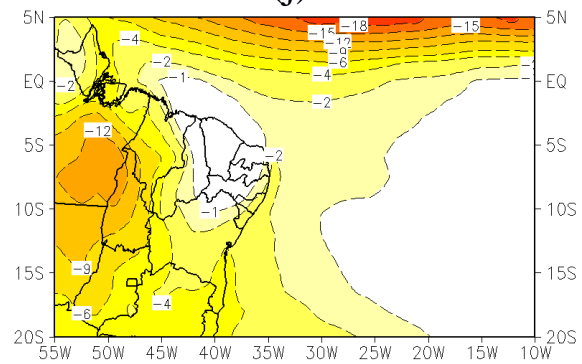

(k)

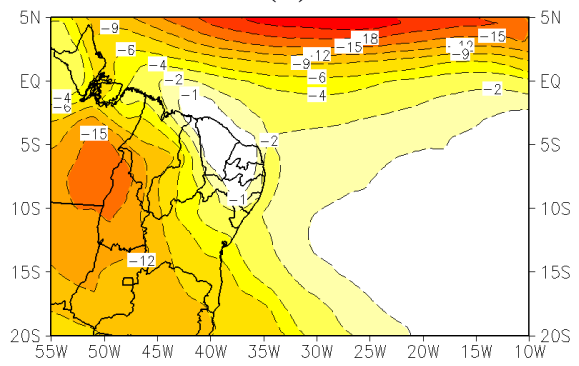

(1)

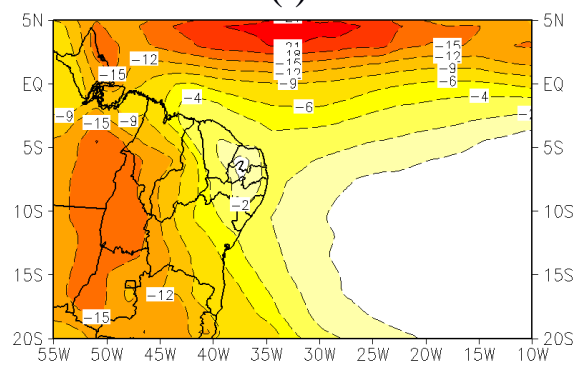

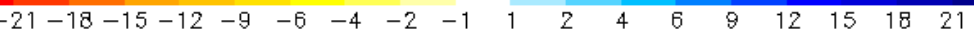

Fig. 4 Monthly precipitation anomalies ( $\mathrm{mm}$ ) from ERAI data due to EWD (lag 0 up to lag+4) over NEB and TSA regions for the period 1989-2009. (a) January, (b) February, (c) March, (d) April, (e) May, (f) June, (g) July, (h) August, (i) September, (j) October, (k) November and (l) December.

From the satellite image analysis the EWDs are found to have an average of 5.5 days duration between detection and dissipation over the period (1989-2009), Using the $700 \mathrm{hPa}$ composite fields, the EWDs average lifetime and wavelength are 6 days and $4500 \mathrm{~km}\left(45^{\circ}\right)$, respectively. The mean phase speed is $9.5 \mathrm{~m} . \mathrm{s}^{-1}$. Despite the different methods used, these characteristics are close to those found by Gomes et al. (2015), Pontes da Silva (2011), Diedhiou et al. (2010), Yamazaki and Rao (1977) and others as Table 1 shows.

Table 1 - EWDs mean characteristics over the TSA according to some studies.

\begin{tabular}{|c|c|c|c|c|c|}
\hline $\begin{array}{c}\text { Period } \\
\text { (days) }\end{array}$ & $\begin{array}{c}\text { Wavelenght } \\
(\mathbf{k m})\end{array}$ & $\begin{array}{c}\text { Phase velocity } \\
\left(\mathrm{m}^{\left.-\mathrm{s}^{-1}\right)}\right.\end{array}$ & Levels (hPa) & Methods & Reference \\
\hline $4-6$ & 6000 & 14 & $700-300$ & $\mathrm{v}$, spectral analysis & NEIVA, 1975 \\
\hline 4 & 4000 & 10 & - & Satellite & $\begin{array}{r}\text { YAMAZAKI and } \\
\text { RAO, } 1977\end{array}$ \\
\hline $3-5$ & - & 12 & - & Sounding & KAYANO, 1979 \\
\hline $3-6$ & 6200 & 12 & 850 & v, ROLE, spectral analysis & CHAN, 1990 \\
\hline 4 & $3500-4500$ & $10-13$ & $1000-500$ & $\mathrm{v}, \mathrm{EOF}$ e EEOF & ESPINOZA, 1996 \\
\hline $3.5-3.8$ & $2900-3800$ & $9.8-11.6$ & 700 & $\mathrm{v}$, composites, satellite & MOTA, 1997 \\
\hline $3-6$ & - & - & $850-500$ & $\mathrm{v}$, sounding & COUTINHO, 1999 \\
\hline
\end{tabular}




\begin{tabular}{rcccrr}
5 & 4000 & 10 & 850 and 700 & $\begin{array}{r}\text { v, satellite, sounding } \\
\text { Spectral analysis, v, }\end{array}$ & $\begin{array}{r}\text { TORREDS, } 2008 \\
\text { DIEDIOU et al., }\end{array}$ \\
$3-9$ & $2000-4000$ & $6-12$ & 700 & composites & 2010 \\
5.3 & 4306.8 & 9.5 & $1000-200$ & $\mathrm{v}, \mathrm{u}, \mathrm{w}$, composites, synoptic & PONTES DA \\
5.5 & 4500 & 9.5 & $1000-200$ & analysis & SILVA, 2011 \\
\hline
\end{tabular}

4

The relative vorticity (RV) and wind anomalies are presented in Figs. 5 (1000 and $850 \mathrm{hPa}$ ) and 6 (700 and 500 $\mathrm{hPa}$ ), respectively. At $850 \mathrm{hPa}$, a cyclonic center is already propagating over the TSA (near $12^{\circ} \mathrm{S}-28^{\circ} \mathrm{W}$ ) at day -2 with a less significant perturbation at $1000 \mathrm{hPa}$ over the same location (Figs. 5a and 5f). This cyclonic center is visible at both levels in the following days and continues moving westward, gaining strength, especially at $850 \mathrm{hPa}$, with a RV minimum of $-2.25 \times 10^{-5} \mathrm{~s}^{-1}$ at day -1 (Figs. $5 \mathrm{~b}$ and $5 \mathrm{~g}$ ). This center intensifies on day 0 at both 1000 and $850 \mathrm{hPa}$ (Figs. $5 \mathrm{c}$ and $5 \mathrm{~h}$ ). The center and trough at $1000 \mathrm{hPa}$ reach the coast at day +1 , but at $850 \mathrm{hPa}$ they reach the coast at day 0 (Figs. $5 \mathrm{~d}$ and $5 \mathrm{~h}$ ), indicative of the wave having a westward tilt. From day 0 to day +2 , the centers move along the NNEB (Figs. 5c-e and 5h-j).

At $700 \mathrm{hPa}$, the cyclonic anomalous center and trough are stronger than the ones seen at other levels. They move westward between days -2 and +2 with a RV minimum around $-3 \times 2 \times 10^{-5} \mathrm{~s}^{-1}$ at days -2 and -1 , as they move through Northeast Brazil (Figs. 6a-e). The EWD signal at this level is so strong and frequent, that one can see a second center and trough propagating over the TSA between days 0 and +2 (Figs. 6c-e). At the $500 \mathrm{hPa}$ level, Pontes da Silva (2011) found the RV and wind anomalies to be quite noisy. Here, the cyclonic RV anomaly and winds can be seen between days -2 and +1 (Figs. 6f-i), reaching the ENEB coastline at day -1 . At $200 \mathrm{hPa}$, the RV and circulation anomaly fields (not shown) indicate no clear EWD signal, but the circulation pattern before they reach ENEB shows a favorable environment, since the flow is from the east (days -2 to -1 ; not shown).

In summary, the composites of anomalies of cyclonic RV and winds associated with EWDs are clearly identified at low levels, with the strongest centers at $700 \mathrm{hPa}$. The middle levels $(500 \mathrm{hPa})$ also play an important role in EWD activity with cyclonic circulation and negative RV centers from the TSA through to the ENEB. Higher levels do not show significant RV anomalies, but the mean flow remains easterly, which means that the EWDs over the TSA have a deep eastern flow feedback. This is an important factor in the maintenance of EWDs according to Riehl (1945).

(a)

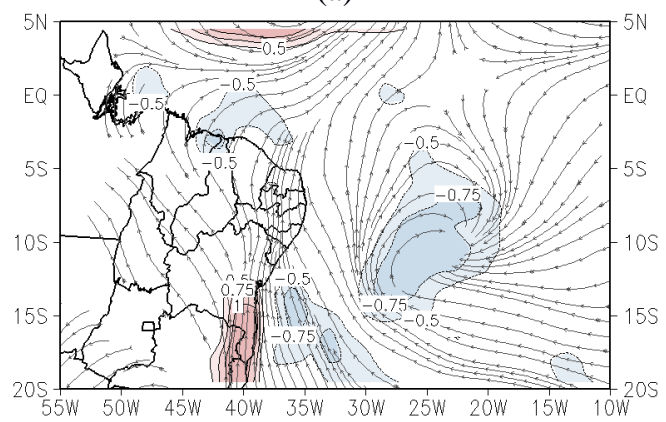

(b)

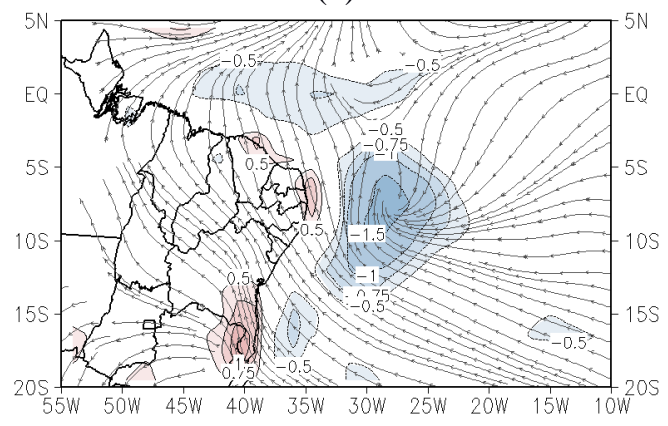

(c)

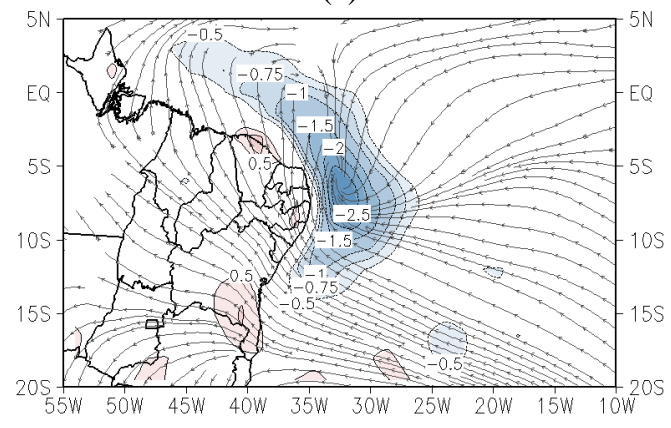

(f)

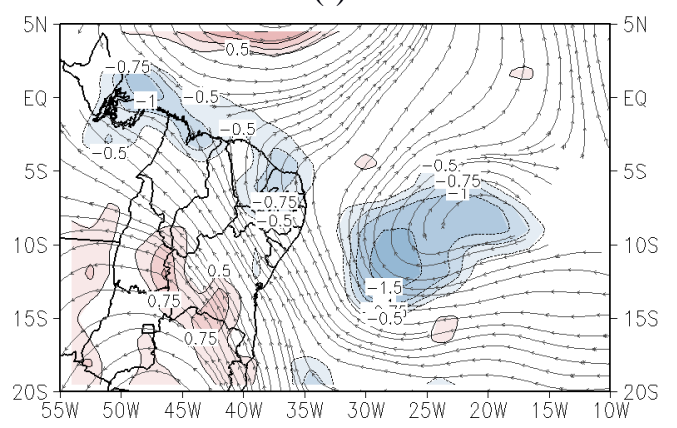

(g)

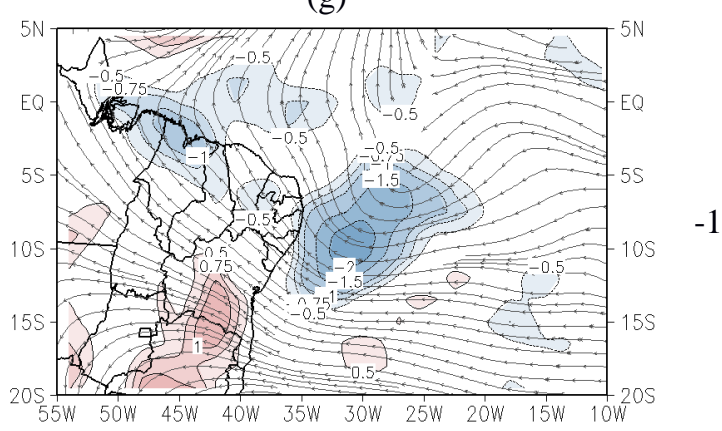

(h)

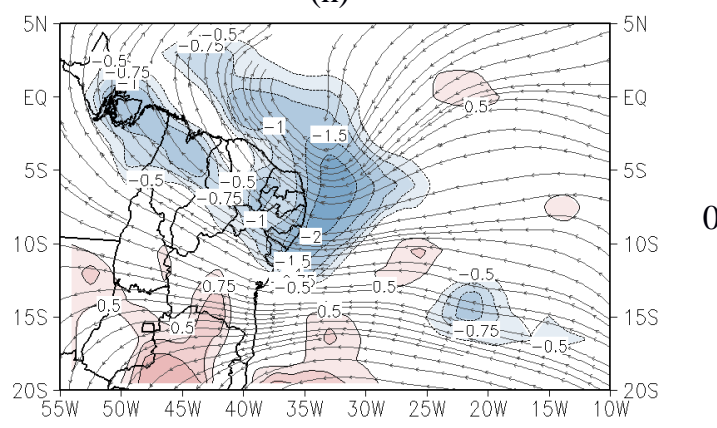


(d)

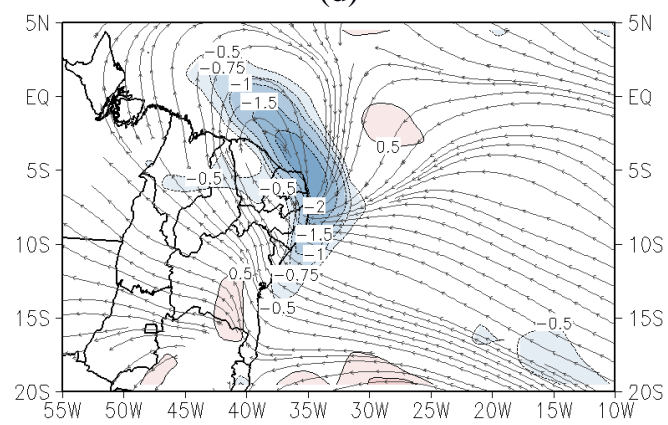

(e)

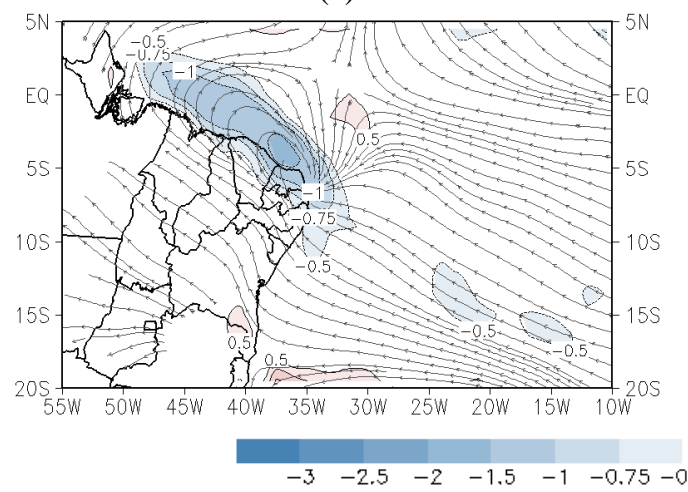

Fig. 5 Composites of relative vorticity (shaded, $10^{-5} \mathrm{~s}^{-1}$ ) and streamline anomalies in the period from April to August 1989-2009 at $1000 \mathrm{hPa}$ (left column) and $850 \mathrm{hPa}$ (right column). The labels are: (a;f) lag -2 , (b;g) lag $-1 ;(\mathrm{c} ; \mathrm{h})$ lag $0,(\mathrm{~d} ; \mathrm{i})$ lag +1 and $(\mathrm{e} ; \mathrm{j})$ lag +2 .

(a)

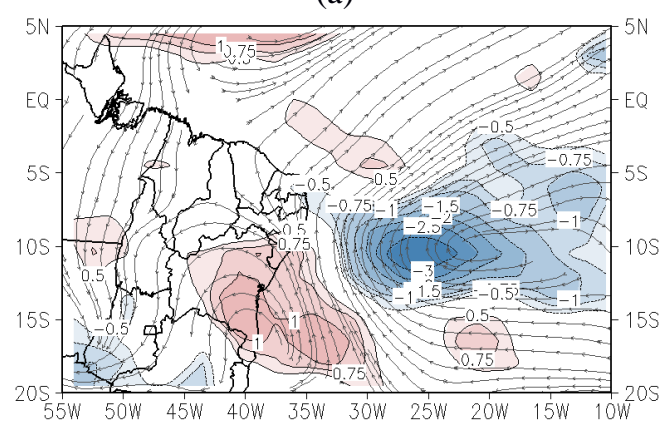

(b)

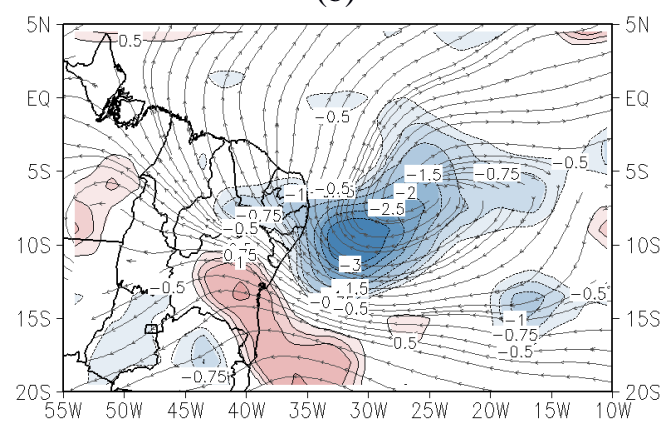

(c)

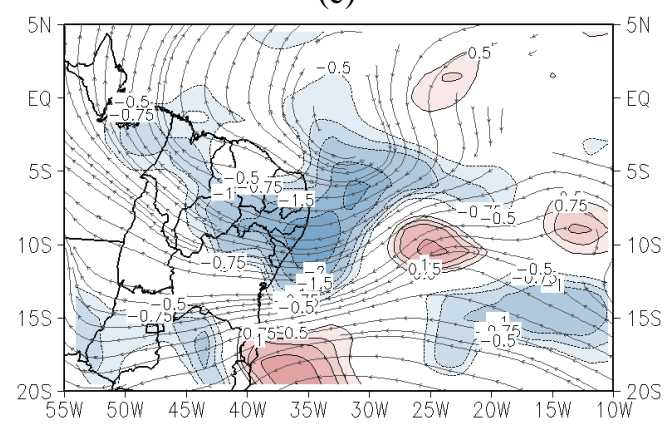

(i)

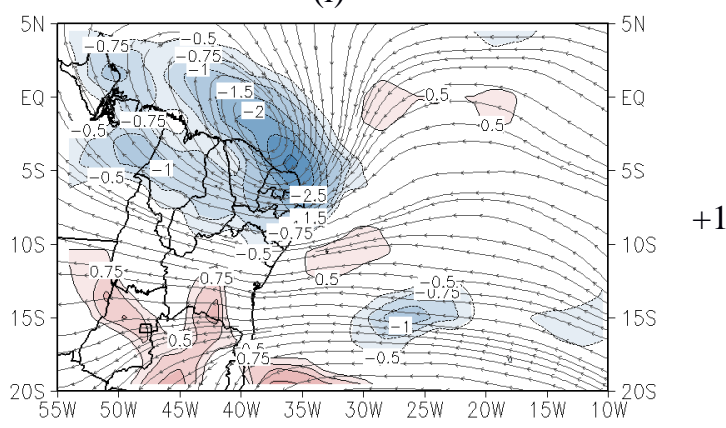

(j)

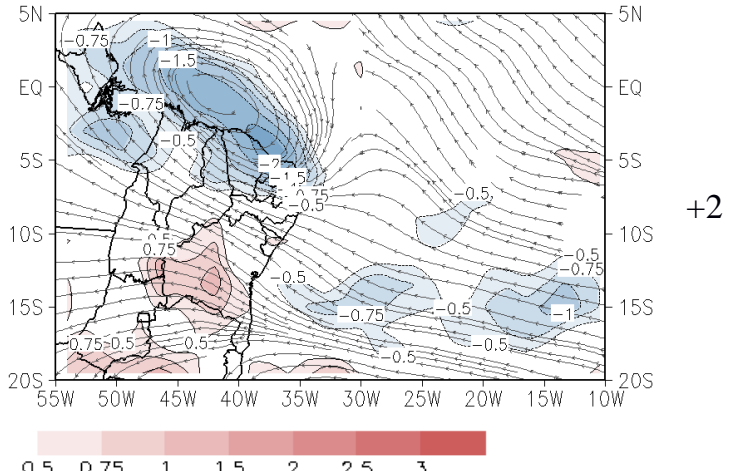

(f)

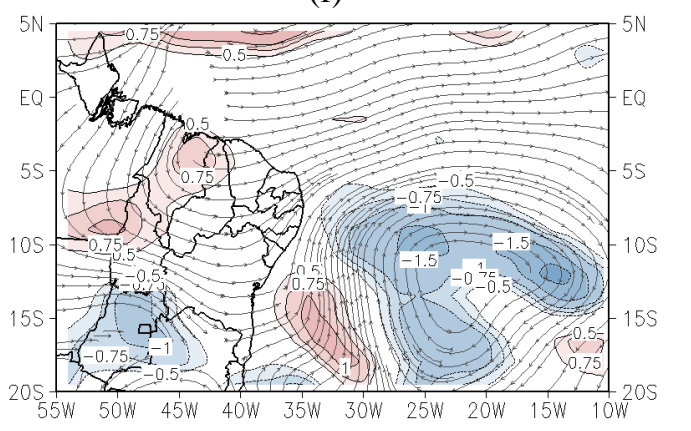

(g)

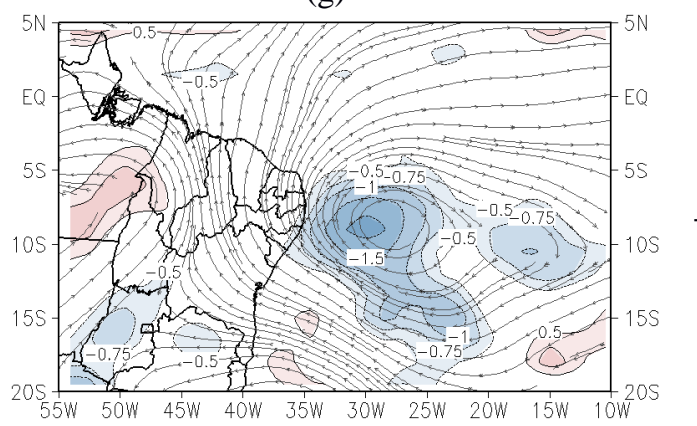

(h)

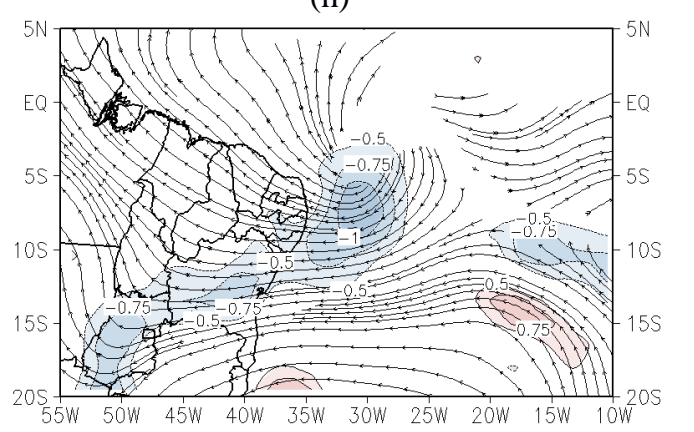


(d)

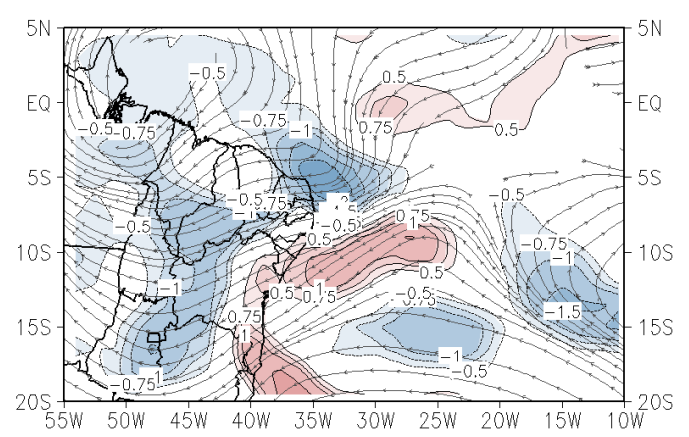

(e)

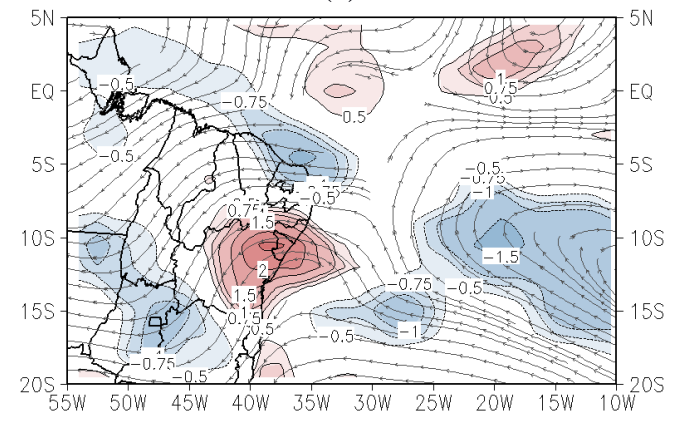

(i)

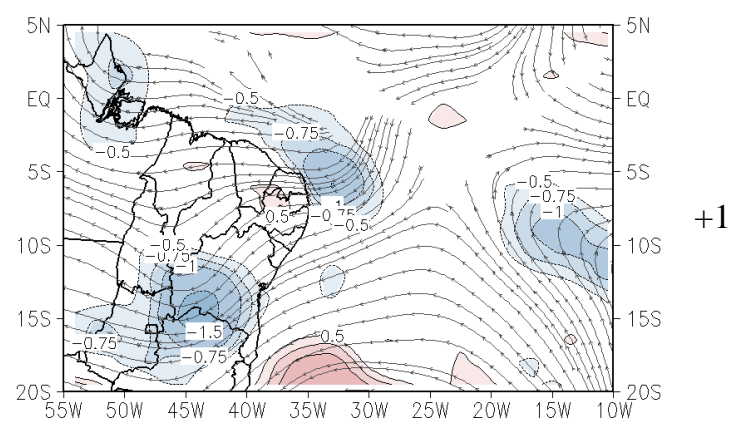

(j)

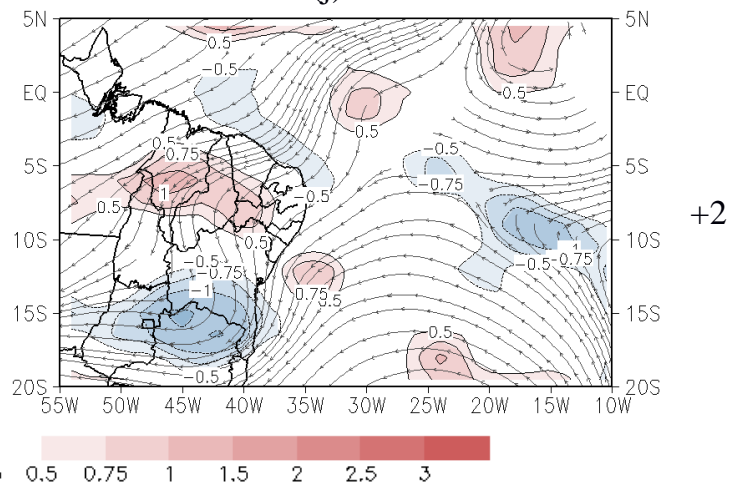

Fig. 6 As in Fig. 4, but for $700 \mathrm{hPa}$ (left column) and $500 \mathrm{hPa}$ (right column) levels.

The convergence and streamline anomalies are presented in Figs. 7 (1000 and $700 \mathrm{hPa}$ ). The centers of the divergence anomalies at low levels are stronger than at other levels. At $1000 \mathrm{hPa}$ (Fig. 7a-e) there is a convergence center propagating to the ENEB behind a divergence center by day -2 over the TSA (near $\left.10^{\circ} \mathrm{S}-22^{\circ} \mathrm{W}\right)(\mathrm{Fig}$. $7 \mathrm{a})$. This center gets stronger and propagates westward and intensifies from day -1 to day +1 (Fig. $7 \mathrm{~b}-\mathrm{d}$ ). The $850 \mathrm{hPa}$ level (Fig. not shown) does not clearly show any propagating divergence or convergence centers.

On the other hand, at $700 \mathrm{hPa}$ (Fig. 7f-j) a divergent center can be seen moving westward behind a weak convergent center, in particular, between days -2 and day +1 (divergence maximum), lingering over the ENEB till day +2 (Figs. 7f-j). At $500 \mathrm{hPa}$ the convergence/divergence anomalies are very weak (not shown), but there is divergence near the ENEB at $200 \mathrm{hPa}$ between days 0 and +2 . These fields show that convergence at $1000 \mathrm{hPa}$ and divergence at $700 \mathrm{hPa}$ are the EWDs most prominent signals at low levels. This kind of convergence/divergence horizontal structure suggests that the TSA EWDs are mostly shallow, agreeing with Pontes da Silva (2011) and Gomes et al. (2015).

(a)

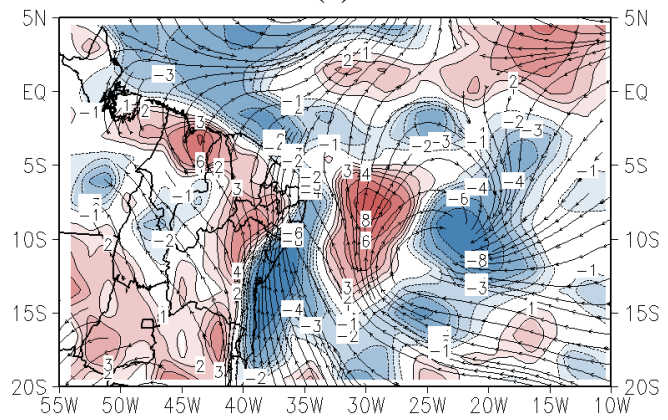

(b)

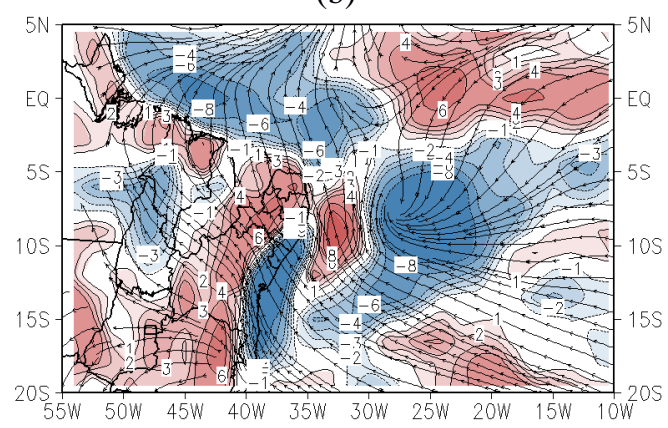

(c) (f)

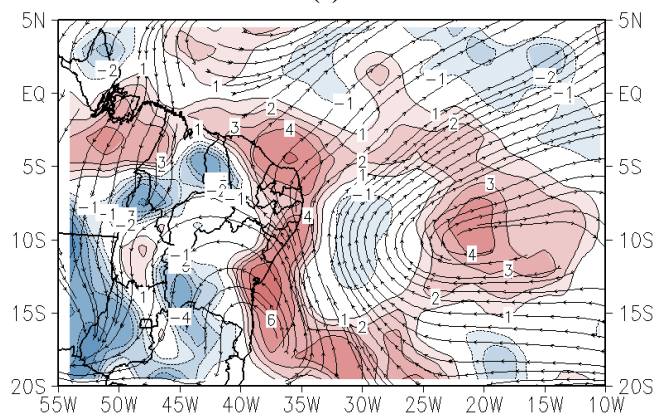

(g)

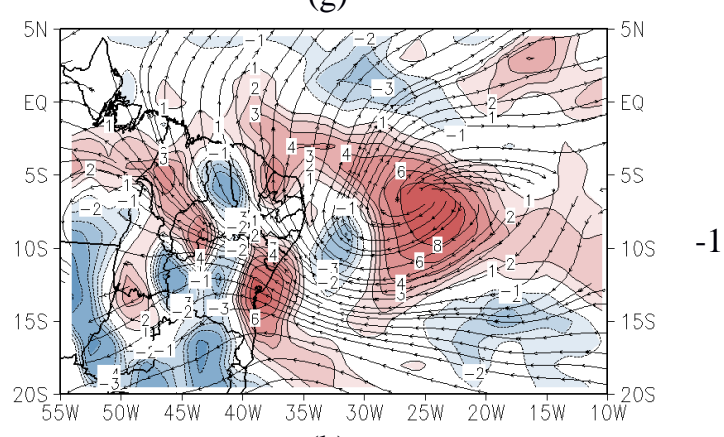

(h) 


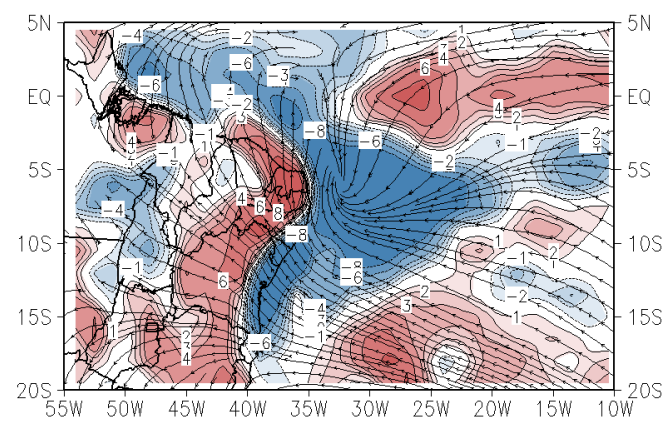

(d)

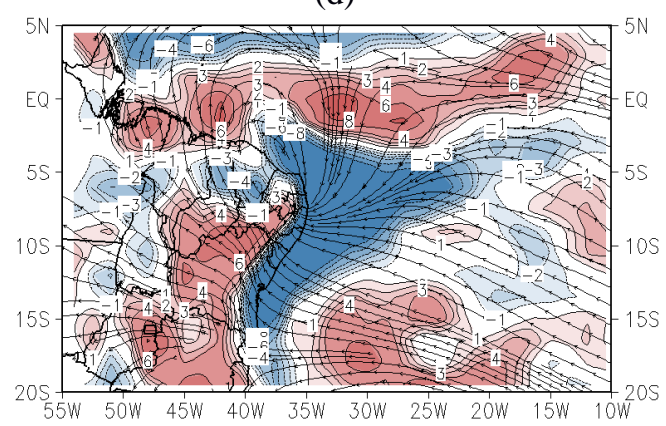

(e)

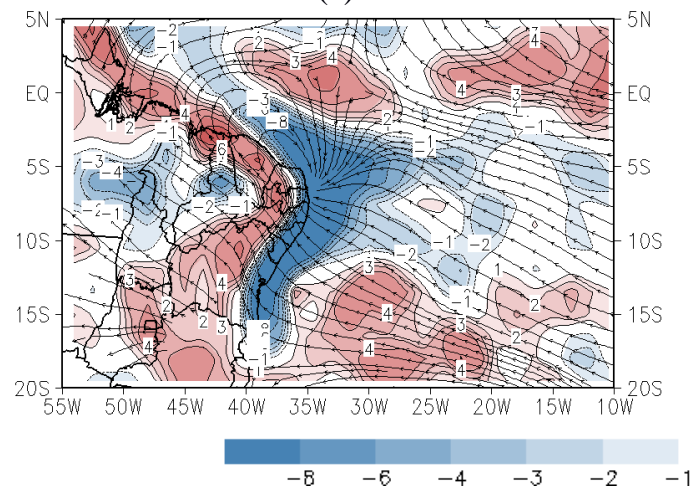

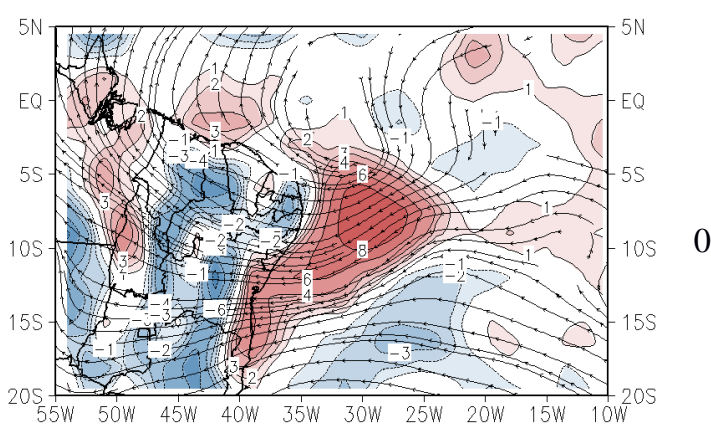

(i)

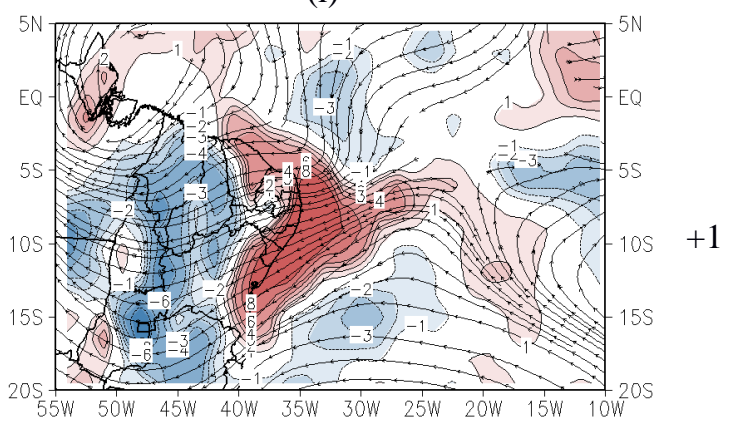

(j)

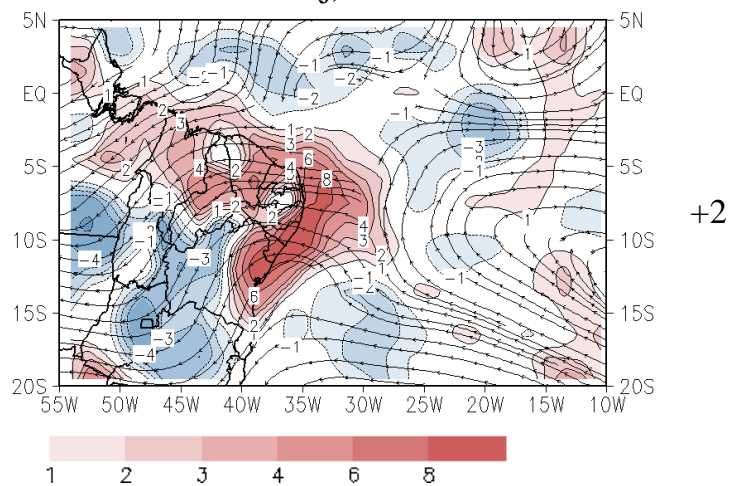

Fig. 7 Composites of horizontal divergence $\left(10^{-5} \mathrm{~S}^{-1}\right)$ and streamlines anomalies in the period from April to August 1989-2009 at $1000 \mathrm{hPa}$ (left column) and $700 \mathrm{hPa}$ (right column) levels. The labels are: (a;f) lag $-2,(\mathrm{~b} ; \mathrm{g})$ lag -1 ; (c;h) lag $0,(\mathrm{~d} ; \mathrm{i}) \operatorname{lag}+1$ and (e;j) lag +2 .

Observing the horizontal wind composites between 1000 and $500 \mathrm{hPa}$ one can see (at least between 700 and $500 \mathrm{hPa}$ ) that the TSA EWDs have a slightly eastward tilt with height, also found by Serra (2008).

Figs. 8 show cross sections of the humidity and omega anomalies at $7^{\circ} \mathrm{S}$. This latitude is chosen since the central EWDs maxima are mostly found in the horizontal fields at this latitude. The initial positive relative humidity center at day -2 is near $20^{\circ} \mathrm{W}$, at around $850 \mathrm{hPa}$ (Fig. 8a). At that time, a negative center is near to the ENEB coastline. Both centers move westward until day +2 (Figs. 8b-e), showing an increase in relative humidity (RH) over ENEB $\left(\sim 35^{\circ} \mathrm{W}\right)$ as the EWDs approach, mostly in the layer of $800-600 \mathrm{hPa}$. Cross-sections of omega anomalies at $7^{\circ} \mathrm{S}$ are also shown in Figs. 8f-j. A weak negative omega (ascent) anomaly between the 900 and $700 \mathrm{hPa}$ levels on day -1 close to $\sim 25^{\circ} \mathrm{W}$ (Fig. $8 \mathrm{~g}$ ) intensifies on day 0 near the ENEB $\left(\sim 35^{\circ} \mathrm{W}\right.$; Fig. $\left.8 \mathrm{~h}\right)$. On day +1 , the ascent anomaly is stronger over the ENEB (Fig. 8i), but becomes weaker over the following days. There is a negative omega center between 900 and $800 \mathrm{hPa}$ (maximum upward motion). The RH and omega anomalies clearly show the EWDs influence along their propagation over the TSA until they reach the ENEB coastline, since the RH center intensifies and increases vertically as the negative omega does the same. 


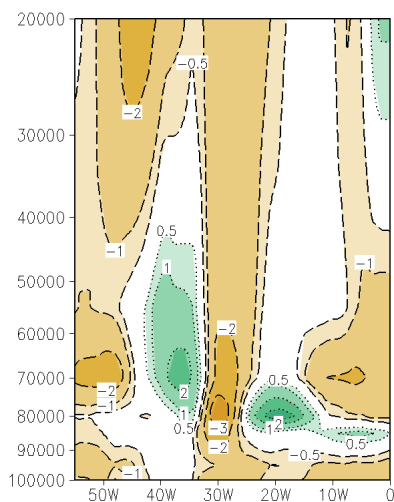

(b)

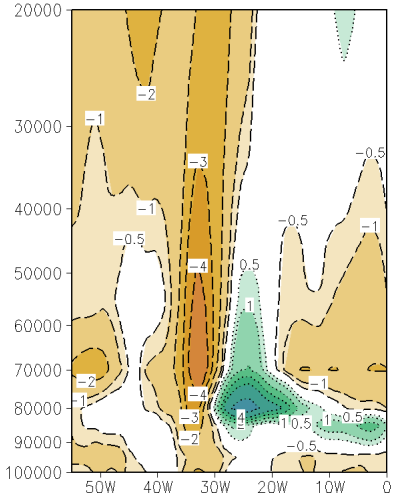

(c)

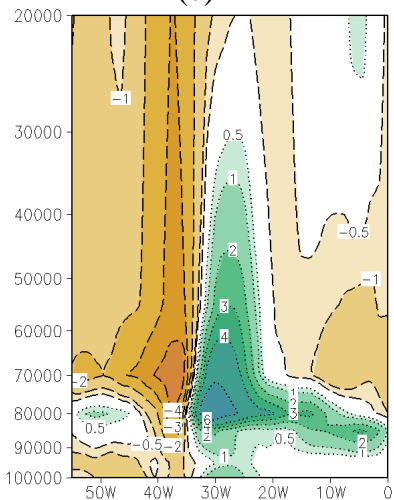

(d)

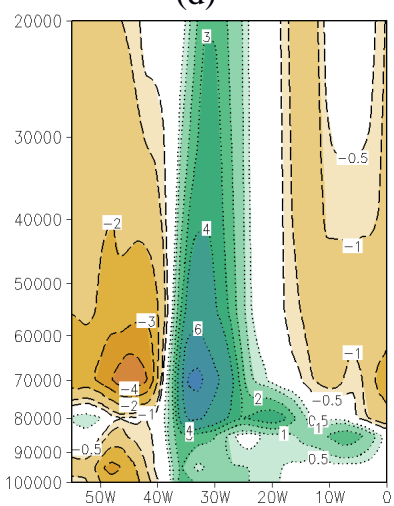

(e)

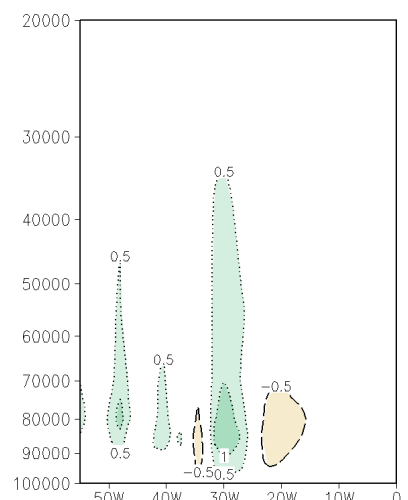

(g)

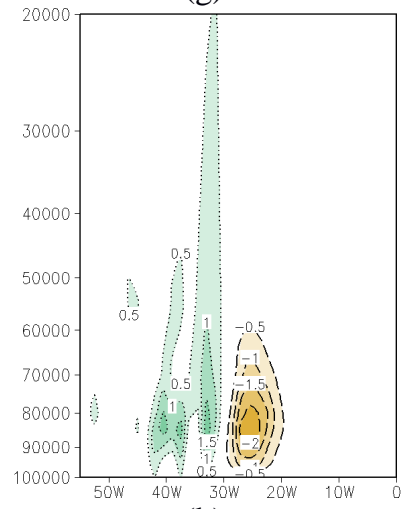

(h)

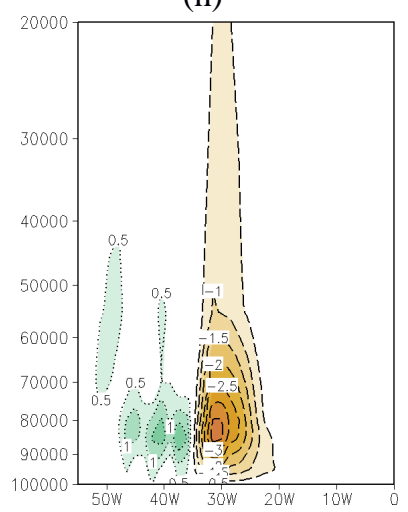

(i)

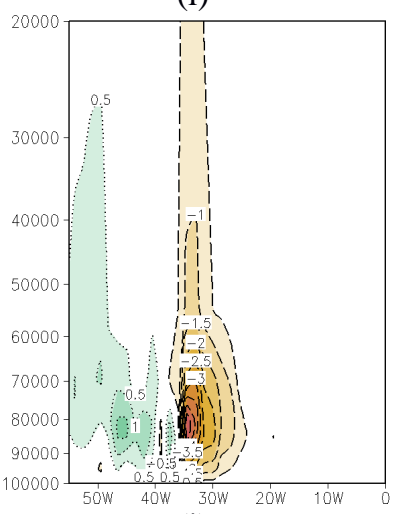

(j) 

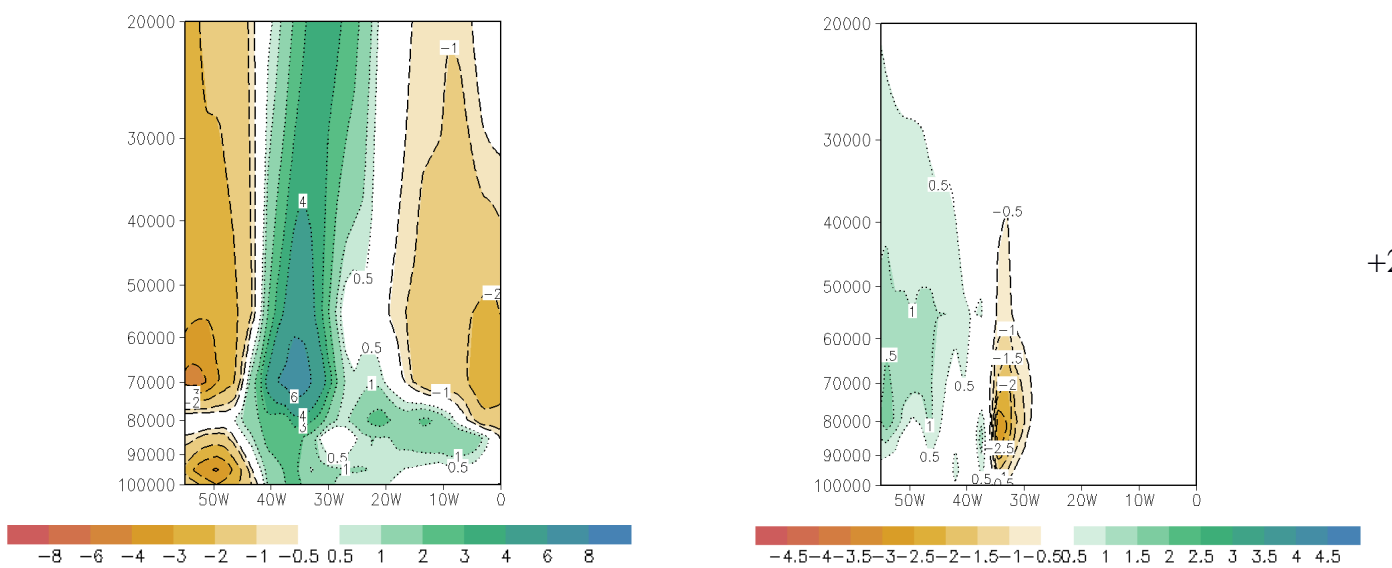

Fig. 8 Vertical cross-sections composite anomalies along $7^{\circ} \mathrm{S}$ of the relative humidity (\%, left column) and omega ( $\mathrm{Pa} / \mathrm{s}$, right column) in the period from April to August 1989-2009. The labels are: (a;f) lag -2 , (b;g) lag -1 ; (c;h) lag $0,(\mathrm{~d} ; \mathrm{i})$ lag +1 and $(\mathrm{e} ; \mathrm{j})$ lag +2 . Contours dashed (dotted) represent negative (positive) values.

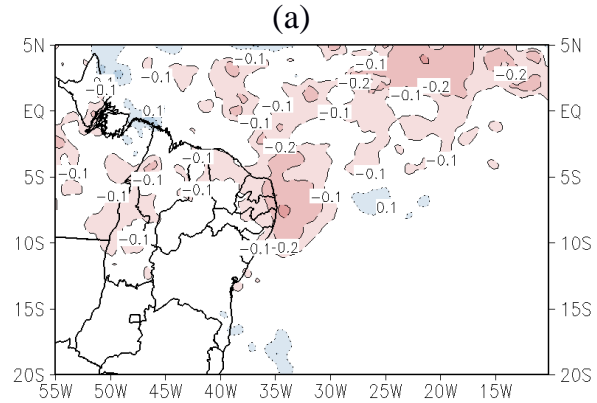

(b)

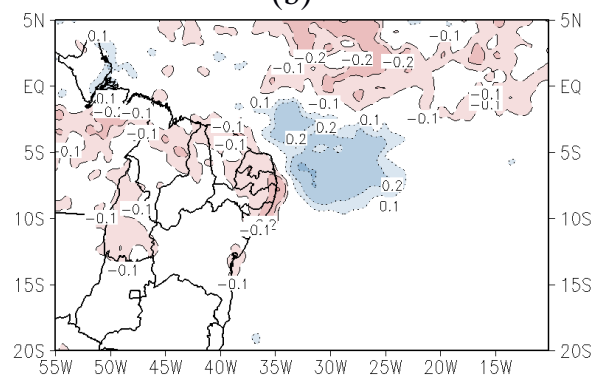

(c)

The precipitation anomalies obtained from TRMM and ERAI, as well as the outgoing longwave radiation (OLR) anomalies for day -2 until day +2 are shown in Fig. 9 and indicate the EWDs path over the TSA. Through a comparative analysis between the TRMM (Fig. 9, left column) and ERAI (Fig. 9 center column) precipitation results, it was observed that the positive precipitation anomaly associated with the EWDs were similar, as well as the negative precipitation anomalies on the north and south Atlantic Ocean and inside the NEB. Near the ENEB, the rainfall anomaly is negative between days -2 and -1 (Figs. 9a-b, 9f-g) and the OLR is positive over the ENEB at day -1 (Fig. 91). Over the TSA, a positive precipitation center in ERAI (and TRMM) spreads from $\sim 8^{\circ} \mathrm{S}, 29^{\circ} \mathrm{W}\left(\sim 7^{\circ} \mathrm{S}, 31^{\circ} \mathrm{W}\right)$ at day -1 to $\sim 7^{\circ} \mathrm{S}, 35^{\circ} \mathrm{W}\left(\sim 8^{\circ} \mathrm{S}, 35^{\circ} \mathrm{W}\right)$ at day 0 , reaching the ENEB coastline with a maximum precipitation center of at least 5 mm day ${ }^{-1}$ (Figs. 9a-e and 9f-j). Figs. 9m-o show a negative OLR center spreading from $\sim 8^{\circ} \mathrm{S}-30^{\circ} \mathrm{W}$ at day 0 and reaching the ENEB coastline at day +1 , i.e., the OLR center anomaly seems to be a little displaced at day 0 compared to the precipitation. There are almost no positive precipitation anomalies over the BA state coast, indicating that this ENEB area is less affected by EWDs. The precipitation (OLR) anomalies are still positive (negative) until day +2 . It is important to highlight that the precipitation and OLR minimum displacement is due to the fact that much of the precipitation is associated with shallow clouds. In all composites, one can see that the typical east-west rainfall anomaly band over the north Atlantic Ocean $\left(\sim 2-5^{\circ} \mathrm{N}\right)$ is likely associated with the ITCZ but has a negative (positive) signal along $\sim 0-3^{\circ} \mathrm{N}\left(\sim 4-5^{\circ} \mathrm{N}\right)$. This shows that most EWDs are not directly associated with the ITCZ, but to other synopticscale systems, such as cold fronts or waves along the TSA Subtropical Ridge northern edge.

(f)

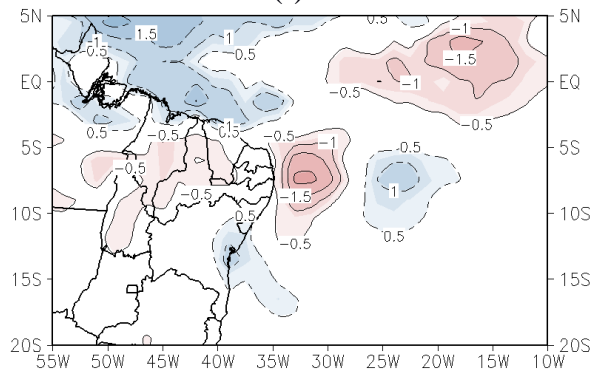

(g)

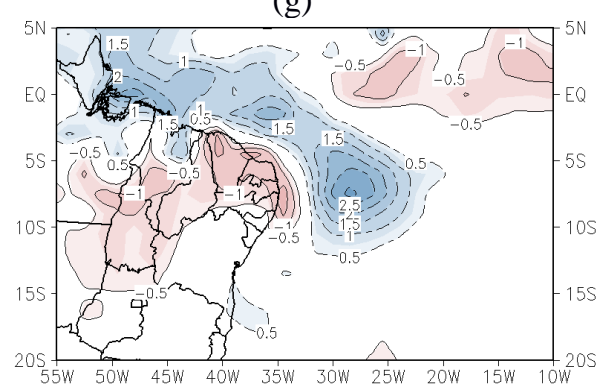

(h) (k)

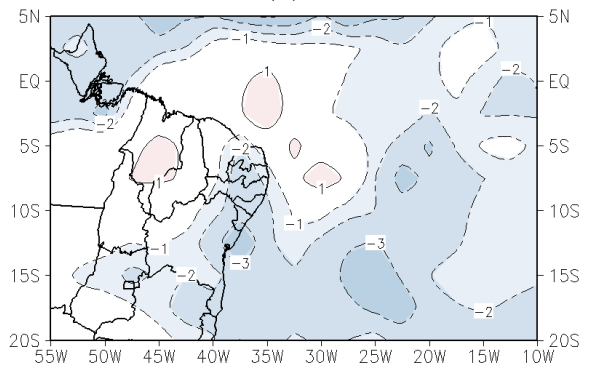

(1)

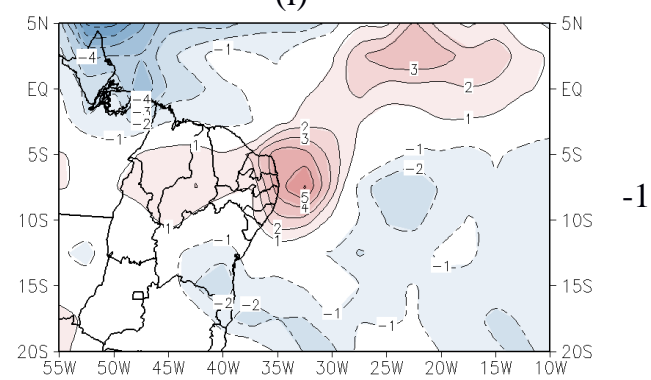

(m) 


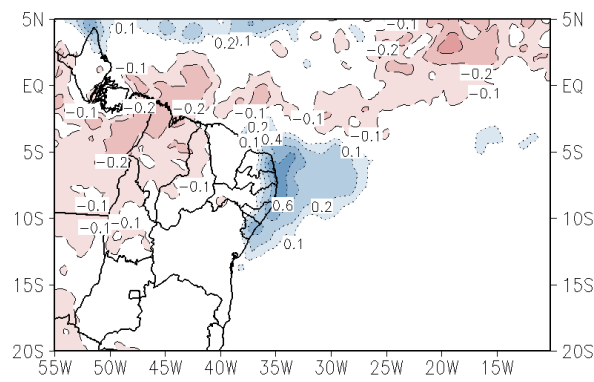

(d)

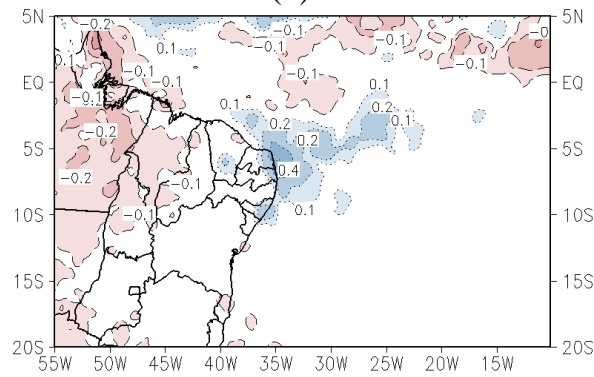

(e)

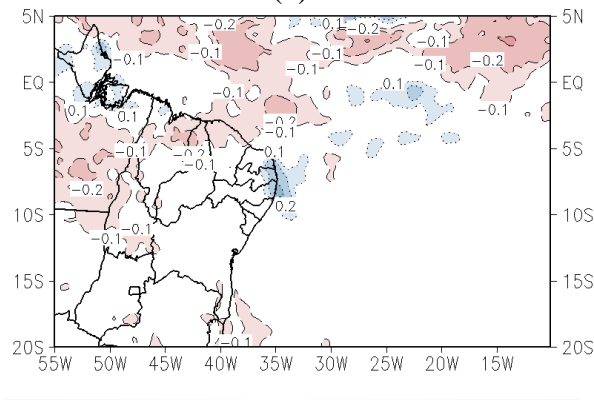

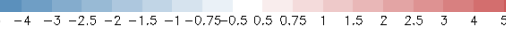

Fig. 9 Precipitation (mm/day) from TRMM (left column) and ERAI (center column) and NOAA outgoing longwave radiation (right column) composite anomalies in the period from April to August 1989-2009. The labels are: (a;f;k) lag -2, (b;g;l) lag -1; (c;h;m) lag 0, (d;i;n) lag +1 and (e;j;o).

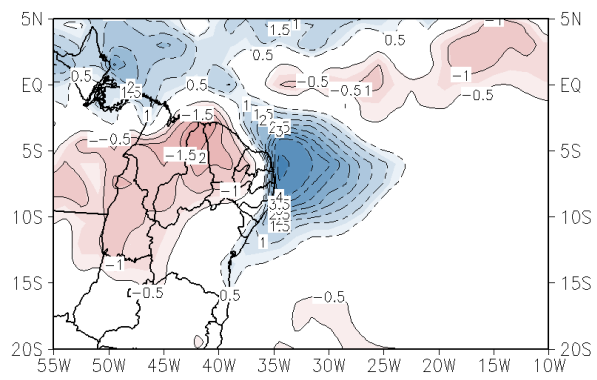

(i)

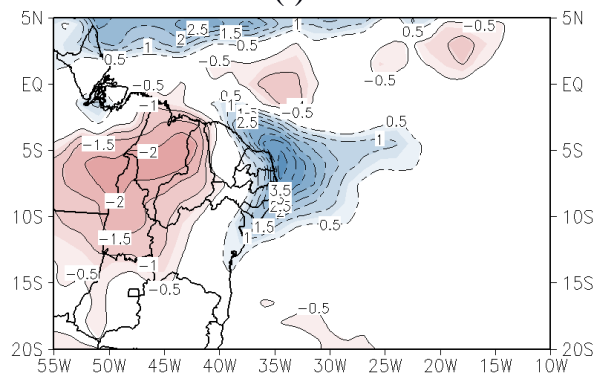

(j)

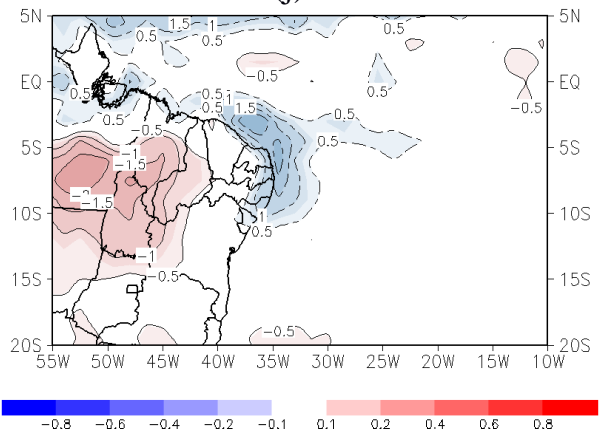

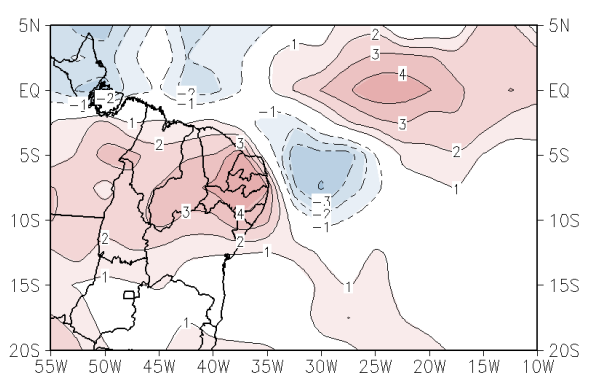

(n)

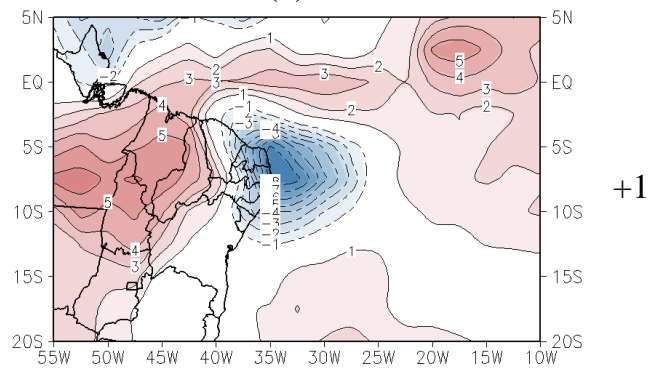

(o)

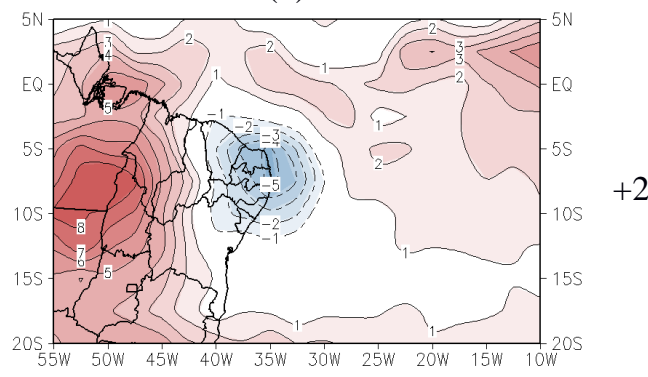

$+2$

The ratio (\%) between the precipitation observed during the composition days (lag-4 up to lag+4) and the total precipitation over NEB and TSA regions from ERAI data in the period from April to August (a) and September to March (b) 1989-2009.is shown in Figure 10a. The EWDs account for at least 60\% of the total rainy season (AMJJA) precipitation in a narrow ENEB area, from the AL state coast to the eastern RN. Furthermore, the ERAI data indicates that the EWDs account for $50 \%$ of the AMJJ rainfall between eastern BA and the eastern RN, including the whole SE and AL. This result is similar to the findings of Pontes da Silva (2011) with regards to the EWD contribution to the ENEB rainy season. Fig. 10b shows the dry season (September to March) ratio between the total precipitation due to EWDs and the total precipitation. Most of the precipitation due EWDs seems to be concentrated over the TSA $\left(\sim 9^{\circ} \mathrm{S}-\right.$ $28^{\circ} \mathrm{W}$, up to $18 \%$ of the total) and over RN (around $16 \%$ of the total), i.e., as expected, there is almost no EWD precipitation contribution through the dry season.

(a)

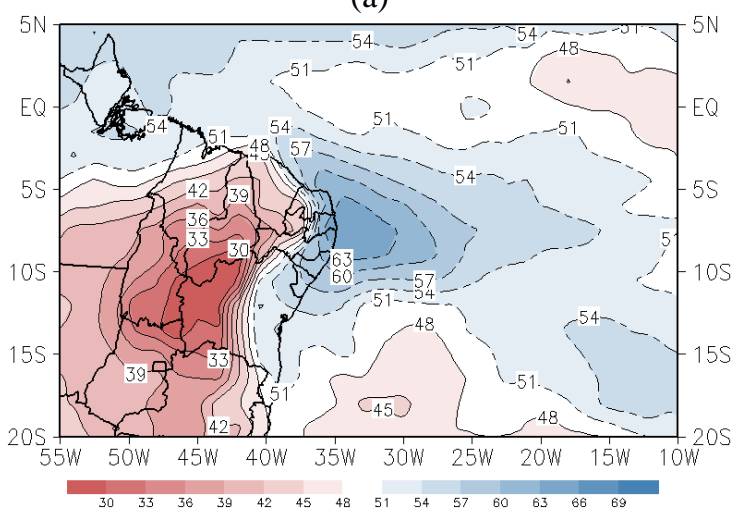

(b)

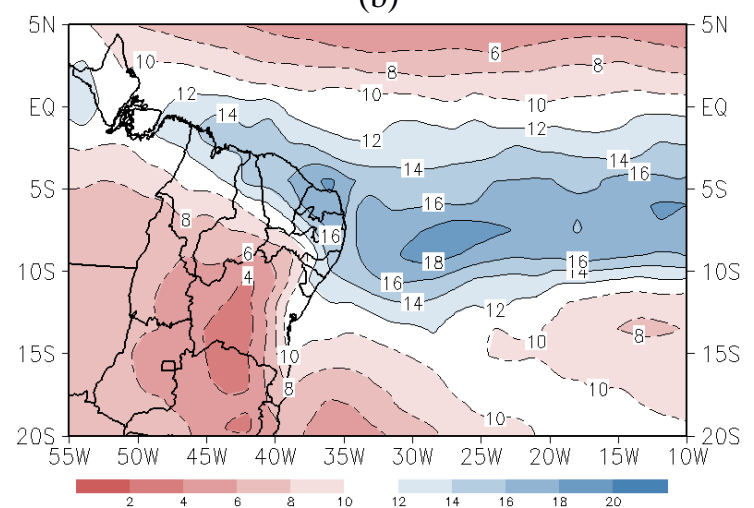

Fig. 10 Ratio $(\%)$ between the precipitation observed during the composition days (lag-4 up to lag+4) and the total precipitation over NEB and TSA regions from ERAI data in the period from April to August (a) and September to March (b) 1989-2009. 


\section{EWDs tracking climatology: statistics and validation}

It has recently been confirmed by Gomes et al. (2015) that EWDs usually have lower amplitudes over the TSA than those observed in the Northern Hemisphere and are better detected at $850 \mathrm{hPa}$ by the automatic tracking algorithm (hereafter called TRACK), where the relative vorticity centers are most intense. Recognizing this fact, we present a description and interpretation of the 21-yr climatological EWD tracking statistics at $850 \mathrm{hPa}$ to contrast with the manual EWD identification. From this we can have a better perspective of the typical EWD life cycle, including initiation, growth and decay, and basic storm track information and evaluate how well the automated tracking performs in identifying EWDs when applied to reanalysis data.

The 518 observed EWDs cases based on the 1989-2009 period were detected by TRACK. This was done by comparing each RV center tracked (dates and paths) with the observed cases. For the system to be characterized as a tracked event, its path had to persist for at least 6 time steps, as well as the latitudes and longitudes associated with them should be in phase with the observed case cloudiness (satellite images) and trough axis (wind fields at 850 and $700 \mathrm{hPa}$ ) Thus, from the 518 manually detected EWDs, 342 (66\%) RV center tracks were detected. Most cases not tracked (34\%) had their formation very close to the coast, and thus the tracks are removed by the track filtering which removes tracks that do not satisfy the minimum lifetime (less than 1.5 days) or travel distance (less than 500km). A detailed description of the criteria used can be found in Gomes et al. (2015). Using TRACK, the EWD average lifetime and wavelength are 4 days and $4000 \mathrm{~km}\left(40^{\circ}\right)$, respectively. The mean phase velocity is between $8-10 \mathrm{~m} \cdot \mathrm{s}^{-1}$. These results agree with those identified by the subjective method. For example, using the satellite image (700 hPa composite fields) an average lifetime of 5.5 (6) days was found, and the average wavelength and phase velocity are $4500 \mathrm{~km}\left(45^{\circ}\right)$ and $9,5 \mathrm{~m} . \mathrm{s}^{-1}$.

Figure 11 shows the 342 negative RV tracks based on the $1989-2009$ period at $850 \mathrm{hPa}$. It can be seen that the $\mathrm{RV}$ centers were detected from about $15^{\circ} \mathrm{W}$ and predominantly travel in the southeast (east)/northwest (west) direction. It is also noticed that there are two preferred paths of propagation, one acting perpendicular to the $\mathrm{ENEB}\left(5^{\circ} \mathrm{S}, 15^{\circ} \mathrm{S}\right)$ and another parallel to the NNEB $\left(5^{\circ} \mathrm{S}, 5^{\circ} \mathrm{N}\right)$. The trajectories which reach the ENEB are mainly associated with the CFs, UTCV systems, while the NNEB are related to AF and ITCZ. A detailed analysis of individual tracks also confirms that some tracks cross the NEB region and reach the Amazon region, (section 3.1).

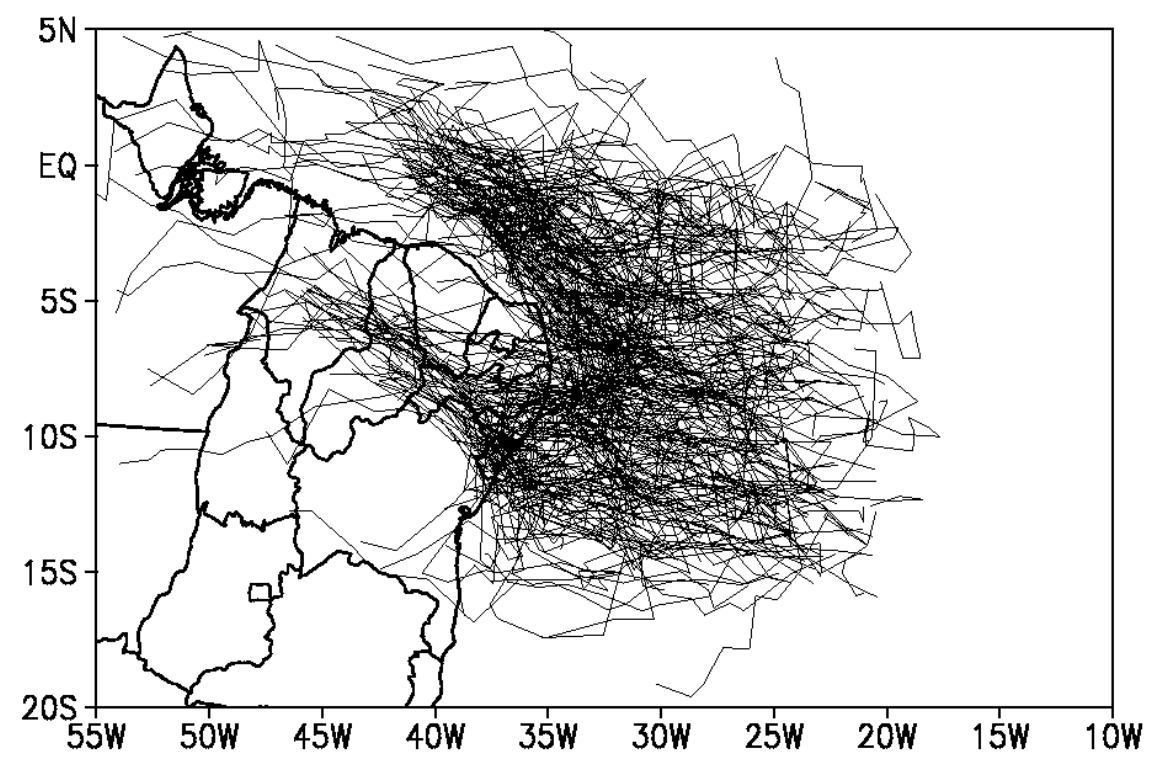

Fig. 11 - Cyclonic vorticity center tracks on the ERAI data (1989-2009) for all EWDs detected at $850 \mathrm{hPa}$.

\section{Summary and Conclusions}

A comprehensive 21-yr climatology of EWD activity over the TSA has been examined, including their frequency by year, month and the type of meteorological systems from which they originate. Additionally, we investigated the interannual variability of EWDs and their relationship with ENSO episodes, as well as cloudiness and the EWDs that reached the Amazon. The synoptic-scale and dynamic characteristics associated with EWDs were investigated for the ENEB rainy (April-August) season by composite analysis. During the study period 518 EWDs observed cases were identified, these showed notable interannual variability with around 16-40 episodes, an average of 25 EWDs/year, a standard deviation of around 6 and an average lifetime of 4-6 days. Other identified EWD life cycle characteristics were average wavelength and phase velocity of $4500 \mathrm{~km}$ and $9.5 \mathrm{~m} . \mathrm{s}^{-1}$, respectively, which are very close to those found by Gomes et al. (2015), Pontes da Silva (2011), Diedhiou et al. (2010), Yamazaki and Rao (1977) and others (wavelength around $4400 \mathrm{~km}$, phase speed of $\sim 11 \mathrm{~m} \cdot \mathrm{s}^{-1}$ and period of $\sim 5$ days).. This higher interannual 
variability found in this research compared to similar studies (Pontes da Silva, 2011) is very likely due the longer observational analysis period (21 years). Of these 518 cases, 97\% (504) reached the ENEB at some point in their evolution, 64\% (330) presented significant convective features and 14\% (70) moved across over the NEB region and reached the Amazon region. The climatological characteristics were examined and the main conclusions are summarized as follows.

- Annual EWDs occurrence tends to be lower (higher) during El Niño (La Niña) years, especially in years with stronger or prolonged ENSO episodes.

- Monthly EWD occurrence has higher activity between the months of April and August (429 cases; rainy season) compared to the other months (89 cases; dry season). August (64 cases) has a similar occurrence to April (66 cases), though the cloud features associated with EWDs were in most cases shallow, representing nearly half the observed cases in the dry season. In October-December the EWDs are very rare (less than 5 cases).

- The system types from which the EWDs originate were associated with five systems: CFs (72,20\%), $\mathrm{AF}$ $(10,04 \%)$, ITCZ $(6,37 \%)$, UTCV $(1,54 \%)$. They also originate through the interaction between AF/CF $(2,90 \%), \mathrm{AF} / \mathrm{ITCZ}(3,47 \%), \mathrm{AF} / \mathrm{VCAN}(0,39 \%)$ and ITCZ/CF $(3,09 \%)$. The main system associated with the origin of EWDs are CFs, where $92 \%$ are formed in the rainy season and $61 \%$ are convective. During the dry period, $9 \%$ of EWDs were associated with CFs, while the convection is rare.

- Results for the automated tracking agree with those identified by the manual tracking, where the tracks that reach ENEB were mainly associated with the CFs and UTCV systems, while on the NNEB we highlight AF and ITCZ.

Relative vorticity, horizontal wind (streamlines), divergence, vertical cross-sections of relative humidity and omega and precipitation composite anomalies are investigated in this paper as the primary large-scale environmental parameters associated with the seasonal variation in EWD characteristics. Cyclonic RV and wind were clearly identified at low levels, with strongest centers at $700 \mathrm{hPa}$ during the rainy period. At middle levels $(500 \mathrm{hPa})$ an important role of the cyclonic circulation and negative RV centers was observed from the TSA through to the ENEB. In contrast, higher levels did not show any significant RV and western circulation. According to Riehl (1945), a deep eastern flow is an important factor to the maintenance of EWDs, meaning that the higher levels circulation over the TSA found here may difficult the EWDs formation and propagation at that region, resulting in weaker waves that the ones seen over other regions. The convergence $(1000 \mathrm{hPa})$ and divergence $(700 \mathrm{hPa})$ fields indicate that the most prominent signals of EWDs occurs at low levels. This kind of horizontal divergence structure suggests that the EWDs over the TSA are mostly shallow, agreeing with Pontes da Silva (2011) and Gomes et al. (2015). The vertical structure clearly shows the EWDs are coherent over the TSA until they reach the ENEB coast, since RH centers intensify and increase vertically as the negative omega does the same. For precipitation, for all composite days one can see that the typical east-west rainfall band over the NAT $\left(\sim 2-3^{\circ} \mathrm{N}\right)$ is likely associated with the ITCZ with a negative signal. This confirms that most EWDs are not directly associated with the ITCZ, but to other synoptic-scale systems, such as cold front tropical intrusions or waves over the TSA Subtropical Ridge northern edge. The EWDs account for at least $60 \%$ of the total rainy season (AMJJA) precipitation in a narrow ENEB area, from the AL's coast to the eastern PB. Furthermore, the ERAI data indicates that EWDs account for 55\% of the AMJJA rainfall between eastern BA and the eastern RN, including the whole SE and AL. This result is similar to the findings of Pontes da Silva (2011) with regards to the EWDs contribution to the ENEB rainy season.

The automatic tracking algorithm was applied to better understand the life cycle of EWDs characteristics over the TSA. Over the 1989-2009 period a total of 342 EWDs were detected. The 175 (34\%) EWDs cases not included were due to their formation close to the coastal regions, so that the tracks didn't satisfy the criteria for minimum life time and traveled distance. We have also shown that several other minimum RV centers were identified by TRACK, which are associated with other types of weather systems. This is due to adjustments made to the algorithm to capture the EWDs, which have lower amplitude on the SAT compared to NAT (Gomes et al. 2015). Future work will explore the other types of RV centers in more detail and explore other criteria for detection. Based on the 342 individual tracks there is a predominance of tracks observed in the southeast (east)/northwest (west) direction with formation around $15^{\circ} \mathrm{W}$. Two preferred paths were also noticed, one perpendicular to the ENEB and another parallel to the NNEB.

A further investigation is required to obtain a better understanding of the life cycle, especially related to its genesis. To do this, we will explore different explore different identification criteria, inter-compare EWDs in different reanalysis products to assess uncertainty, explorer how EWDs may change in the future using climate change simulations.

Acknowledments This study was supported by Conselho Nacional de Desenvolvimento Científico e Tecnológico, CNPq (Grant nos. 143207/2009-1 and 304298/2014-0) and Fundação de Amparo à Pesquisa do Estado de São Paulo, FAPESP, Brazil (Grant no. 08/58101-9). Pedro L. Silva Dias acknowledges the CNPq support through grant No. 309395/2013-5. We thank the two reviewers for their very helpful comments which encouraged us to improve the analysis and present a comparison between subjective and objective tracking. 


\section{References}

Asnani GC (1993) Tropical meteorology. Published by GC Asnani, Pune, India, 1202 pp.

Berry FA, Bollay and Norman E, Beers R (1945) Handbook of meteorology. McGraw-Hill Book Company, London

Berry G, Thorncroft C (2007) African easterly waves during 2004 - analysis using objective techniques. Mon Weather Rev 135:1251-1267

Burpee RW (1972) The origin and structure of easterly waves in the lower troposphere of north African. J Atmos Sci 29:77-90

Caetano JMV (2011) Analysis of easterly waves on the east coast of northeastern Brazil for the period between 1999 and 2009. Master dissertation, Federal University of Rio de Janeiro. (in Portuguese)

Carlson TN (1969) Some remarks on African disturbances and their progress over the tropical Atlantic. Mon Weather Rev 97:716-726

Chan CS (1990) Analysis of easterly wave disturbances over the south equatorial Atlantic Ocean. Master dissertation, National Institute of Space Research. (in Portuguese)

Coutinho EC, Fisch G (2007) Easterly wave disturbances (EWDs) at the region of Alcântara Launching Center - MA. Brazilian Journal of Meteorology 22(2):193-203. (in Portuguese)

Dee DP et al. (2011), The ERA-Interim reanalysis: configuration and performance of the data assimilation system. Q.J.R. Meteorol. Soc., 137: 553-597. doi:10.1002/qj.828

Diedhiou AS, Machado LAT, Laurent H (2010) Mean kinematic characteristics of synoptic easterly disturbances over the Atlantic. Adv Atmos Sci 27(3):1-17

Duchon CE (1979) Lanczos filtering in one and two dimensions. J Appl Meteor 18:1016-1022

Fedorova N (2008b) Synoptic IV: Systems and processes synoptic over South America. Federal University of Alagoas, Maceió. (in Portuguese)

Gomes HB, Ambrizzi T, Herdies DL, Hodges K, Pontes da Silva BF (2015) Easterly wave disturbances over northeast Brazil: an observational analysis. Adv Meteo. doi:10.1155/2015/176238

Hall BA (1989) Westward - moving disturbances in the south Atlantic coinciding with heavy rainfall events at Ascension Island. Meteor Magazine 118:175-181

Hodges KI (1995) Feature tracking on the unit sphere. Mon Weather Rev 123:3458-3465

Hodges KI (1996) Sperical nonparametric estimators applied to the UGAMP GCM integration for AMIP. Mon Weather Rev 124:2914-2932

Hodges, K. I., 1999: Adaptive constraints for feature tracking. Mon. Wea. Rev., 127:1362-1373

Huffman GJ et al. (2001) Global precipitation at one-degree daily resolution from multisatellite observations. J Hydromet 2:36-50.

Kayano MT (2003) Low-level high-frequency modes in the tropical Atlantic and their relation to precipitation in the equatorial South America. Meteor Atmos Phys 83:263-276

Kousky VE (1979) Frontal influences on northeast Brazil. Mon Weather Rev 107:1140-1153

Kousky VE (1980) Diurnal rainfall variation in northeast Brazil. Mon Weather Rev 108:488-498

Krishnamurti TN (1978) Tropical meteorology. WMO Publ. No. 364, Compendium of Meteorology

Liebman B, Smith CA (1996) Description of a complete (interpolated) outgoing longwave radiation dataset. Bulletin of the American Meteorological Society, 77: 1275-1277 
Lucena DB, Servain J, Gomes Filho MF (2011) Rainfall response in northeast Brazil from ocean climate variability during the secondy half of the twentieth century. J. Clim 24:6174-6184

Merritt NS (1964) Easterly waves and perturbations, a reappraisal. J Appl Meteor 3:367-382

Nobre P, Shukla J (1996) Variation of sea surface temperature, wind stress and rainfall over the tropical Atlantic and South America. J Clim 9:2464-2479

Pezzi LP, Calvalcanti IFA (2001) The relative importance of ENSO and tropical Atlantic sea surface temperature anomalies for seasonal precipitation over South America: a numerical study. Clim Dyn 17:205-212

Pontes da Silva BF (2011) Easterly Waves contribution for the eastern northeast Brazil precipitation: mean synoptic evolution and numerical simulations. Master dissertation, University of São Paulo. (in Portuguese)

Rao VB, Lima M, Franchito SH (1993) Seasonal and interannual variations of rainfall over eastern northeast Brazil. J Clim 6:1754-1763

Raupp, CFM, Silva Dias, PL (2005) Excitation mechanism of mixed Rossby-gravity waves in the equatorial atmosphere: Role of the nonlinear interactions among equatorial waves. Journal of the Atmospheric Sciences, 62,5,1446-1462.

Reed JR, Norquist DC, Recker EE (1977) The structure and properties of African wave disturbances as observed during phase III of GATE. Mon Weather Rev 105:317-333

Reynolds RW, Smith TM (1995) A high resolution global sea surface temperature climatology. J Clim 8:1571-1583

Riehl H (1945) Tropical meteorology. McGgraw-Hill, New York

Santos e Silva CM, Silva A, Oliveira P, Lima KC (2014) Dynamical downscaling of the precipitation in northeast Brazil with a regional climate model during contrasting years. Atmos Sci Let 15:50-57

Santos, IA, Silva Dias, PL, Torres, AR (2002): The role of mixed Rossby-gravity waves on the organization of convection in the Amazon. Preprints, 12th Brazilian Congress of Meteorology, Foz do Iguaçu, Brazil, Brazilian Society of Meteorology, 3995-4001.

Serra YL, Kiladis GN, Hodges KI (2010) Tracking and mean structure of easterly waves over the intra-Americas sea. J Clim 23:4823-4840

Serra YL, Kiladis GN, Cronin MG (2008) Horizontal and vertical structure of easterly waves in the Pacific ITCZ. J Atmos Sci 65:1266-1284

Servain J (1991) Simple climatic indices for the tropical Atlantic Ocean and some applications. J Geophys Res 96(15)137-15 146

Simmons A, Uppala S, Dee DP (2007) Update on ERA-interim. ECMWF Newsletter 111(5)

Simmons A, Uppala S, Dee DP, Kobayashi S (2007) ERA-interim: new ECMWF reanalysis products from 1989 onwards. ECMWF Newsletter 110:25-35

Thorncroft CD (1995) An idealized study of African easterly waves. Part III: more realistic basic states. Q J Roy Meteor Soc 121:1589-1614

Thorncroft CD, Hodges KI (2001) African easterly wave variability and its relationship to Atlantic tropical cyclone activity. J Clim 14:1166-1179

Torres RR, Ferreira NJ (2011) Case studies of easterly wave disturbances over northeast Brazil using the eta model. Weather Forecasting 26:255-235

Trenberth KE (1997) The definition of El Niño. Bull. Amer. Meteor. Soc. 78:2771-2777

Uppala S et al. (2008) Towards a climate data assimilation system: status update of ERA-Interim. ECMWF Newsletter, 115:12-18 
1 Yang GY, Methven J, Woolnough S, Hodges K, Hoskins B (2018) Linking African easterly wave activity with 2 equatorial waves and influence of Rossby waves from the South Hemisphere. J Atmos Sci 75(6):1783-1809

Yamazaki Y, Rao VB (1977) Tropical cloudiness over South Atlantic Ocean. J Meteor Soc Japan 55:205-207. 